LA-UR-01-4562

Approved for public release: distribution is unlimited.

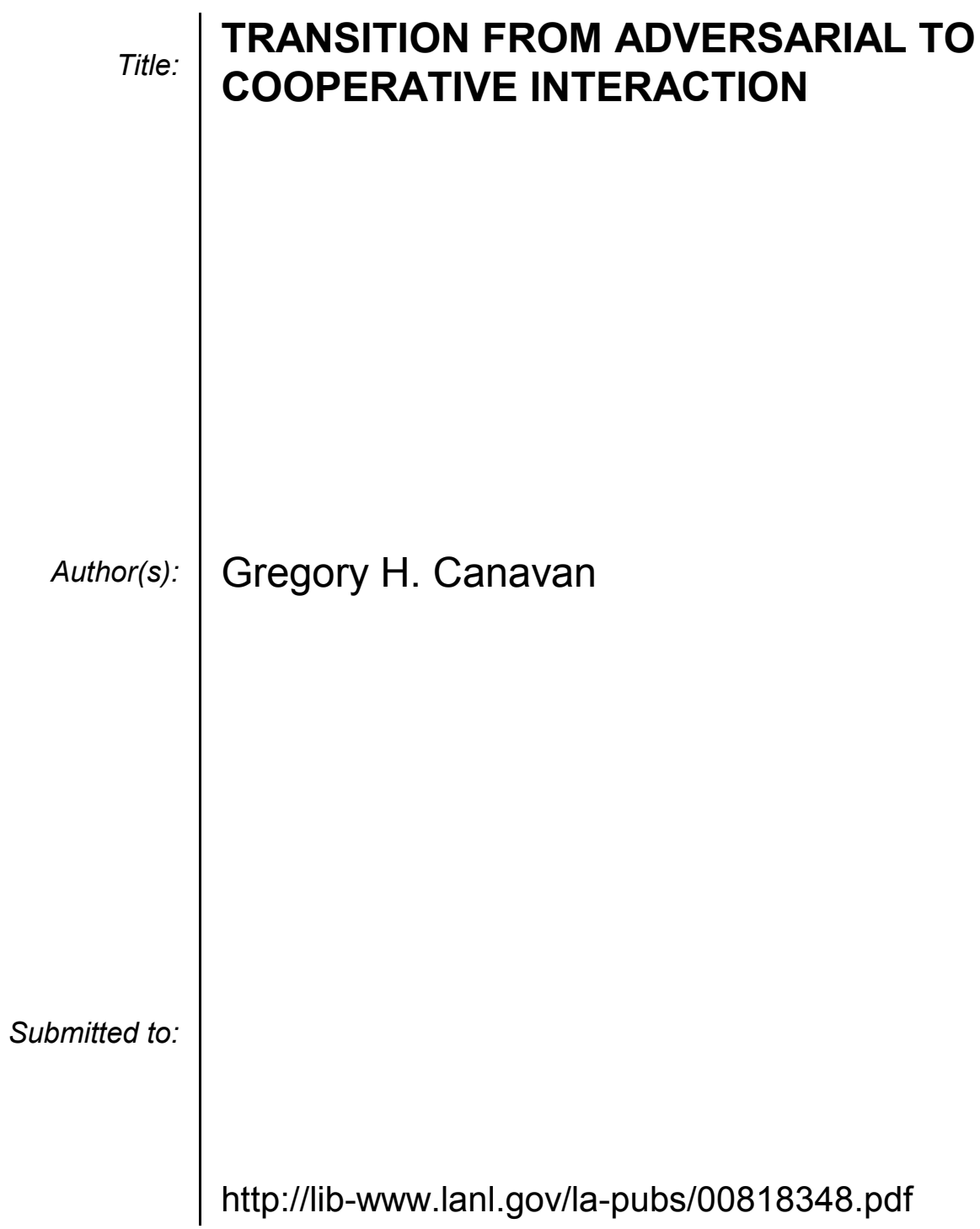

Los Alamos National Laboratory, an affirmative action/equal opportunity employer, is operated by the University of California for the U.S. Department of Energy under contract W-7405-ENG-36. By acceptance of this article, the publisher recognizes that the U.S. Government retains a nonexclusive, royaltyfree license to publish or reproduce the published form of this contribution, or to allow others to do so, for U.S. Government purposes. Los Alamos National Laboratory requests that the publisher identify this article as work performed under the auspices of the U.S. Department of Energy. Los Alamos National Laboratory strongly supports academic freedom and a researcher's right to publish; as an institution, however, the Laboratory does not endorse the viewpoint of a publication or guarantee its technical correctness. 


\title{
TRANSITION FROM ADVERSARIAL TO COOPERATIVE INTERACTION
}

\author{
Gregory H. Canavan
}

Game theoretic analysis of strategic conflicts is extended to interactions between two or more adversaries with realistic target sets. Current offensive configurations are shown to be stable, insensitive to reductions in offensive forces, deployment of limited defenses, and the exchange of offenses for defenses. The transition from adversarial to cooperative interaction improves stability monotonically. The shift of targeting to high value targets stabilizes trilateral configurations, in which defenses lead to a balance between large and small sides resembling a small scale version of that between large sides.

\section{INTRODUCTION}

This note extends the game theoretic analysis of strategic conflicts begun in earlier Seminars on Planetary Emergencies to interactions with and without defenses between two or more adversaries with more realistic target structures. ${ }^{1}$ It reviews the essentials of game theory as applied to the analysis of strategic decisions, the application of first and second strike costs as payoffs, and solution optimization, which resolves several inconsistencies seen with earlier metrics. The stability of the current bilateral offensive configuration is shown to be high and insensitive to deep reductions in offensive forces, the deployment of limited defenses, and the exchange of significant offensive forces for defenses.

The transition from adversarial to cooperative interaction is represented by the progressive reduction of the parameters representing each side's preference for damaging or deterring the other, which monotonically improves stability. Estimates of strike incentives in bilateral and trilateral configurations are reduced by the inclusion of high value targets in both sides' force allocations, which dominates the details of offensive and defensive forces. The shift to high value targets stabilizes trilateral offensive configurations, a result that differs with that from analyses based on military costs only. When defenses are included, they lead to a balance between a large defended side and small undefended side that resembles the balance between two large sides. Including the 
large side's preference for defense of high value targets in the analyses reduces its strike incentives and thus the small side's incentive to preempt. However, it also removes the large sides' ability to deter, so the stability of multi-polar configurations continues to be controlled by the least stable dyad, which places constraints on the size of defenses that can be deployed stably that could be more stringent than those from the bilateral balance.

\section{GAME THEORETIC FRAMEWORK}

Damage and cost models ${ }^{2}$ are derived and discussed in earlier papers. ${ }^{3}$ Strikes are estimated with conventional exchange models Costs are taken to be exponential approximations to the aggregate damage to self and incomplete damage to other, so first and second strike costs are of the form Cost = damage to self $+\mathrm{L}(1$ - damage to other $)$, where $\mathrm{L}$ is a parameter that measures the attacker's relative preference for inflicting damage on the other and preventing damage to self. ${ }^{4}$ If neither side strikes, the cost of inaction to each is $\mathrm{L}$, which is also a measure of the damage each wants to be able to inflict on the other, i.e., the amount of value it wishes to hold at risk to deter the other from untoward action or to force it to comply with some demand. During the cold war, L was large because deterrence was a dominant role of strategic forces. As conflict is replaced by cooperation, $\mathrm{L}$ falls as the deterrent role diminishes and the role of strategic forces is in response to damage to self.

The side that considers striking first minimizes its first strike cost, $\mathrm{C}_{1}$, and then decides whether to strike depending on whether $\mathrm{C}_{1}$ is smaller than the cost of inaction, $\mathrm{L}$. This minimization also determines the optimal allocation of the first striker's weapons between missiles and value targets and the cost of the side that strikes second, $\mathrm{C}_{2}{ }^{5}$

The essentials of game theory for crisis stability are summarized in Fig. 1, which defines a graph of play, the decision nodes, which side decides at each node, and a set of payoffs to both sides for traversing each path. ${ }^{6}$ The nodes represent decisions whether to strike first and strike back, so the first and second strike costs described above are appropriate payoffs. The two sides are identified only as U (unprimed) and P (prime), corresponding to the un-primed and primed symbols used for their forces, strikes, and 
costs. Identification with specific countries cannot be established without specifying their damage objectives, which are imperfectly known.

In the three nodes at the upper right corner, $\mathrm{U}$ can strike first, but $\mathrm{P}$ plays a key role in U's decision. U determines how $\mathrm{P}$ would optimally respond to each of its choices and then chooses the action that minimizes U costs, which also determines P's actions and costs. The top branch is a first strike by $\mathrm{U}$ followed by a second strike by $\mathrm{P}$, which has costs $\left(\mathrm{C}_{1}, \mathrm{C}_{2}{ }^{\prime}\right)$. The second is inaction by $\mathrm{U}$ followed by a strike by $\mathrm{P}$ and restrike by U. On it, $\mathrm{P}$ would not strike for $\mathrm{C}_{1}{ }^{\prime}>\mathrm{L}^{\prime}$, but would for $\mathrm{C}_{1}{ }^{\prime}<\mathrm{L}$ '. Thus, for $\mathrm{C}_{1}{ }^{\prime}>\mathrm{L}^{\prime}, \mathrm{U}$ chooses between $\mathrm{C}_{1}$ from the top branch and $\mathrm{L}$ from the second. If $\mathrm{C}_{1}>\mathrm{L}, \mathrm{U}$ would also choose inaction, neither side would strike, and the costs for the crisis would be (L, L').

If $C_{1}$ ' fell to $L^{\prime}$, $P$ would see an incentive to strike. However, $U$, anticipating that transition, would preempt $\mathrm{P}$ before $\mathrm{C}_{1}$ ' reached $\mathrm{L}$ '. In this way a rational decision by $\mathrm{P}$ to reduce its costs slightly when $\mathrm{L}^{\text {' reaches }} \mathrm{C}_{1}$ ' would induce a rational decision by $\mathrm{U}$ to preempt that imposes larger costs on both sides than inaction, the preferred path if either side controlled all decisions. Moreover, U's decision to preempt depends on its evaluation of P's cost $C_{1}$ ' and damage objective L', neither of which $U$ knows with precision. Thus, imperfect knowledge of the other's decision parameters could cause $\mathrm{U}$ to strike by accident. The difference $\mathrm{C}_{1}$ ' $-\mathrm{L}$ ' represents the margin of safety against such accidental exchanges.

The lower half of the decision tree contains the symmetric branch on which $\mathrm{P}$ decides first. The two halves are combined by a decision as to which of the two sides could strike first in a crisis that is conventionally modeled as a random decision by Nature $(\mathrm{N}),{ }^{7,8}$ which was explored in earlier notes and is represented here by the probability $u$ that $U$ can strike first in a crisis.

\section{BILATERAL ENGAGEMENTS WITH DEFENSES}

Figure 2 shows the cost to $\mathrm{U}$ of reaching node 7 as a function of U's defenses and

the probability that it can strike first in a crisis, u. ${ }^{9}$ Small numbers of interceptors have no impact; even 600 interceptors do not change strike incentives, because the decision variable $\mathrm{C}_{1}-\mathrm{x}$ remains positive. The decision to act is made when the difference 
becoming negative, which produces a strike incentive. Larger numbers of interceptors produce large costs at small $\mathrm{u}$ because $\mathrm{P}$ has and incentive to preempt and does so. At large u, U can strike first and use its defenses to negate P's suppressed second strike. At very large defenses, U's costs are reduced below those of inaction for all $\mathrm{u}$, but those reductions are gained through strong interactions and at large cost to P.

Figure 3 shows the ratio of first to second strike cost, which is often used as a stability index. ${ }^{10}$ The composite index falls rapidly with the number of interceptors. It is reduced about $40 \%$ by 400 . That is largely because U's index falls; P's is largely unchanged. In the game theoretic analysis, small defenses have no impact on stability, but large ones produce an incentive for $\mathrm{P}$ to preempt. In the cost ratio metric, even small defenses degrade indices, and large ones only treat the increase in U's incentive to strike first, which is a less important and unstable mechanism.

\section{TRADING OFFENSES FOR DEFENSES}

Freedom to trade offenses for defenses makes it possible to deploy large defenses without inviting preemption or raising costs. Figure 4 shows the impact of $U$ trading offenses for defenses, starting with START III level U and P offenses, $\mathrm{L}=0.5$, and L' $=$ 1, i.e., fairly aggressive opponents. ${ }^{11} \mathrm{U}$ and P's first strike costs for those forces and damage preferences are the two central curves at large numbers of weapons. If $U$ unilaterally reduced its offensive forces from that level while P maintained its forces at 2,000 , by $\mathrm{U}=500$, that would cause U's first strike cost to increase to $\approx 1.25$ while P's fell to 0.4 . Such a discrepancy would be undesirable, as it could incentivize strikes, given current estimates of damage preferences.

Parenthetically, this result could be inverted to suggest that Russia reducing its forces for economic or other reasons to 500-1,000 weapons while U.S. remained at current levels would produce a situation that Russia could interpret as giving the U.S. an incentive to strike first, depending on the damage preference it attributed to the U.S.

Side U unilaterally adding 1,500 interceptors would reduce U's first strike cost to $\approx 0.1$ and increase $\mathrm{P}$ 's to $\approx 1.5$, which would be unacceptable to $\mathrm{P}$. But $\mathrm{U}$ deploying those defenses and reducing its offensive weapons to 250 weapons would produce the 
intersection at $\mathrm{C}_{1} \approx \mathrm{C}_{1}{ }^{6} \approx 0.8$. Thus, for these conditions it is possible to trade large offenses for defenses without adversely impacting the first strike costs of either side to a significant extent. As first strike costs are their primary decision variables, this means it is possible to trade offenses for defenses without impacting strike incentives, margins, or stability. In this example it is possible to trade 1,500 defensive interceptors for about 1,500 offensive weapons, which implies a tradeoff ratio of roughly 1:1.

Reduced damage preferences make it possible to increase stability margins while trading offenses for defenses. Figure 5 has the same weapons levels as Fig. 4 but less aggressive opponents with $\mathrm{L}=\mathrm{L}^{\prime}=0.25$. The curves without defenses are little changed, so the intersection at large numbers of weapons is at about the same level of cost. However, the margin there is now $\mathrm{C}_{1}-\mathrm{x} \approx 0.85-0.25 \approx 0.6$, which is much larger than that the $\approx 0.85-0.5 \approx 0.35$ of Fig. 4 . Shifting from adversarial to cooperative interaction, as modeled by the reduction of damage preferences in the game theoretic framework, strongly reduces incentives, increasing stability margins.

Comparing Figs. 4 and 5 shows that with defenses, reducing damage preferences significantly increases U's and reduces P's first strike costs. The result is that for 1,000 interceptors, the intersection shifts to about 1,000 weapons, where the costs are $\mathrm{C}_{1} \approx \mathrm{C}_{1}$ 。 $\approx 0.5$. In contrast to Fig. 4 , first strike costs do fall by $\approx 0.45-0.75 \approx-0.3$, but the resulting value of 0.45 still has a margin of $\approx 0.45-0.25 \approx 0.2$, which is almost $100 \%$ with respect to their reduced damage objective. The exchange ratio is again roughly 1:1. It appears possible to deploy large defenses stably by trading offenses for defenses at constant first strike costs, reducing damage objectives, or some combination of the two. Such trades should also make it possible to accommodate changes in the opponent's offenses and defenses with exchange ratios on the order of unity.

\section{BILATERAL OFFENSIVE ENGAGEMENTS AT LOW FORCES}

First and second strike costs at historical and projected force levels were discussed in earlier Workshop reports using cost ratio metrics. ${ }^{12}$ Those analyses imply significant strike incentives at present force levels, explain the modest stability improvements from arms reductions to date, and suggest that strike incentives could grow 
in the deep reductions to 1,000 to 300 weapons postulated by the U.S. National Academy of Sciences. ${ }^{13}$ As weapons become scarce, second strike forces survive, so $\mathrm{C}_{2}$ falls more rapidly than $\mathrm{C}_{1}$ increases. That causes the $\mathrm{u}$-weighted average of $\mathrm{C}_{1}$ and $\mathrm{C}_{2}$ to drop rapidly towards $\mathrm{L}$, which raises the possibility that low force levels could be less stable. The assessment is complicated by the shift of targeting to higher value targets at low forces, which was ignored in earlier analyses. Both effects can be treated by the extension of the previous game theoretic formalism for military value to address target sets that contain both military and high value targets. The formal extension is straightforward. The resulting analysis indicates that the shift to high value targets and fall in second strike costs at low forces do not adversely impact stability. ${ }^{14}$

Figure 6 breaks first and second strikes from symmetric forces at progressively lower total numbers of weapons into strikes on military and high value targets. ${ }^{15}$ For large numbers of weapons, first and second strikes are primarily on military targets, as assumed in previous analyses. At about 1,000 weapons the strikes on military and high value targets are comparable. At lower weapons the strikes shift to high value for obvious reasons: as weapons become scarce, they are reserved for targets with the highest value. The previous conversion of costs into strike incentives remains valid when some or all of the costs are from high value targets. It predicts the low weapon configurations of Fig. 6 remain stable to very low numbers of weapons; however, it also shows that for a as forces are reduced, targeting shifts from military to high value targets for a wide range of damage preferences, which has implications that are not captured by numerical indices.

The extended analysis also makes it possible to study the variation of costs and strike incentives with damage preferences. Figure 7 shows the variation of costs at nodes 1 and 2 with L (= L'), assuming that the two sides have equal preferences for defending $\left(\mathrm{K}=\mathrm{K}^{\prime}=2\right)$ and attacking $\left(\mathrm{V}=\mathrm{V}^{\prime}=1\right)$ high value targets. ${ }^{16}$ The cost to $\mathrm{U}$ for inaction, i.e., not damaging either military or high value targets, is $\mathrm{L}+\mathrm{V}$, which is the bottom curve on Fig. 7. The top curves are the cost to $\mathrm{U}$ and $\mathrm{P}$ for action. As they are far above the costs of inaction for all L, there is no interaction. Moreover, the stability margin grows from $\approx 3-2 \approx 1$ or $50 \%$ at large L to $2.5-1$ or $150 \%$ at small L, so sensitivity to uncertainties is also reduced. 
The parameter K represents U's preference for survival of its high value targets relative to that for the survival of military targets. When $\mathrm{K}$ is small, the analysis defaults to that based on military costs. When it is large, it produces a cost to $\mathrm{U}$ that grows with $\mathrm{K}$ to levels that make inaction preferable. That typically occurs for $\mathrm{K}>1$, as seen above. A strong preference for protecting one's high value increases first strike cost, which undercuts the attacker's motivation for action. V represents U's preference for destruction of P's high value targets, so $\mathrm{V} / \mathrm{L}$ is U's relative preference for the destruction of high and military value targets. When $\mathrm{V}$ is small, $\mathrm{U}$ has little incentive to strike high value targets, and the analysis defaults to the military targets treated earlier. When V is large, U's ability to do significant damage to P's few high value targets gives $U$ an incentive to strike, which typically occurs for $\mathrm{V}>1 .{ }^{17}$

At small forces, attacks shift for obvious economic reasons to higher value targets. As both sides are generally seen as being more interested in the survival of its high value targets than in the destruction of the other's, the values of $\mathrm{K}$ and $\mathrm{V}$ in Fig. 7 should be appropriate through the transition to a cooperative arrangement, in which the primary emphasis is the reduction of $\mathrm{L}$, their damage objectives for military targets.

\section{TRILATERAL OFFENSIVE ENGAGEMENTS}

Previous studies treated the impact on START I level U and P forces of third country (T) forces varying from NAS to START levels under the assumption that all

sides target military value. ${ }^{18}$ The principal result is that the interaction between $\mathrm{U}$ and $\mathrm{P}$ remains essentially bilateral, and hence stable, but that both see a strong incentive to strike $\mathrm{T}$ at force levels below START II, which in turn gives $\mathrm{T}$ a strong incentive to preempt them. For the reasons discussed above, those incentives are eliminated if $\mathrm{T}$ is allowed to target U and P's high value targets, given U and P's apparently strong preferences for survival of their high value targets. Thus, if $\mathrm{T}$ can hold a significant number of them at risk with its relatively few weapons, U and P's strike incentive is eliminated, which in turn eliminates T's incentive to preempt.

Figure 8 shows these trends quantitatively. ${ }^{19}$ As U's preference to reduce damage to its high value targets, $K$, increases, the cost to $U$ for striking first increases, and the 
advantage to T for preemptively striking U's high value targets decreases. For $\mathrm{K}<4$, U has a strike incentive like that for military targets discussed earlier and $\mathrm{T}$ has a strong incentive to preempt, so there is a strong and costly preemption and restrike. By $K \approx 4, U$ has little incentive to strike first, but $\mathrm{T}$ still has an incentive to preempt, although doing so increases costs to both of them far above those for inaction. For $\mathrm{K}>5$, $\mathrm{U}$ no longer has an incentive to strike, which removes T's incentive to preempt.

The elimination of U's strike incentive at $K \approx 5$ is due to the increase with $K$ in the cost associated with a given level of damage to U's high value targets. Increasing K ultimately produces a level of cost that removes U's incentive to strike first. Stability is achieved by $\mathrm{T}$ being able to deter $\mathrm{U}$ with its relatively few weapons by directing them to U's high value targets; thus, the balance between $U$ and $T$ resembles that between $U$ and $\mathrm{P}$, although on a much smaller scale. The stability of the triad is still determined by that of the least stable dyad, although it is improved by U's concern for high value targets. ${ }^{20}$

\section{TRILATERAL INTERACTIONS WITH DEFENSES}

Previous reports studied the impact of defenses on trilateral force structures in which U and P have START I and T has NAS 1 (1,000 weapon) level forces. ${ }^{21}$ The interaction between $\mathrm{U}$ and $\mathrm{P}$ resembles their bilateral interaction, i.e., modest defenses had no impact, but large defenses produce preemption by $\mathrm{P}$, in accord with Fig. 2. The interaction between $\mathrm{U}$ and $\mathrm{T}$ gives $\mathrm{U}$ an incentive to strike, but $\mathrm{T}$ no incentive to preempt, so $U$ would use its offenses in conjunction with its defenses to suppress $T$, if it could. However, for nominal damage preferences, the barrier from P's potential preemption at large defenses prevented $U$ from deploying the defenses needed to suppress $T$. The result is to limit U's defenses, produce a largely offensive balance between $U$ and $P$, and allow $\mathrm{T}$ to increase its forces from current low levels without constraints.

However, P's preemption barrier to U's deployment of large defenses can be removed by the freedom to trade offenses for defenses discussed above and illustrated in Figs. 4 and 5. Thus, it is useful to examine the resulting relationship between $U$ and $T$. Figure 9 shows the costs to $\mathrm{U}$ and $\mathrm{T}$ at node $7 .{ }^{22}$ For up to $\approx 4$ interceptors, the interaction between $U$ and $T$ is stable; neither sees an incentive to strike. At 6 interceptors, $U$ has an 
incentive to strike, which decreases its cost slightly but increases T's greatly. At 8 to 10 interceptors, T has an incentive to preempt, which strongly raises costs to both. By 12 interceptors, T's strike costs increases enough that its strike incentive is lost, but $\mathrm{U}$ still sees an incentive to strike, which it does, reducing its cost but maintaining T's at a high level thereafter.

The basic shape of the curves for $\mathrm{U}$ and $\mathrm{T}$ in Fig. 9 is the same as those for $\mathrm{U}$ and $\mathrm{P}$ in Fig. 2 for intermediate $\mathrm{u}$, as are the underlying reasons. Allowing $\mathrm{T}$ to target $\mathrm{U}$ 's high value targets gives it an incentive to preempt at levels of $U$ defenses that would negate T's second strike forces, which produces a barrier in the U-T relationship similar to that in the U-P relationship, which restricts the levels of defenses that $\mathrm{U}$ can stably allocate to the U-T portion of the P-U-T triad. These calculations use preferences $\mathrm{K}=20$ and $\mathrm{V}^{\prime}=1$, which tend to favor the number of interceptors that can be allocated stably. Values that emphasize targeting military value predict instability, as before. Increasing U's preference for the protection of high value targets removes its incentives to strike by increasing the cost of damage to U's high value. That increases stability, but at the price of U's ability to deter untoward action by $\mathrm{T}^{23}$

\section{SUMMARY AND CONCLUSIONS}

This note extends the game theoretic analysis of strategic conflicts begun in earlier Seminars to interactions with and without defenses between two or more adversaries with more realistic target structures. Game theory is sufficiently flexible to treat all current issues in strategic force reduction and defensive deployments under discussion with sufficient fidelity through the variation of a few readily identifiable preference parameters. The analysis sheds light onto a number of contradictions in previous cost ratio analyses such as the U.S. appearing to be the source of instability in the current bilateral offensive configuration, small defenses seeming to have a large impact on stability, and the current trilateral balance being unstable. The stability of the current bilateral offensive configuration is shown to be high and insensitive to deep reductions in offensive forces, deployment of limited defenses, and the exchange of offensive forces for defenses. 
The transition from adversarial to cooperative interaction, as represented by the progressive reduction of each side's damage preference parameters, monotonically improves stability and margins. Inclusion of high value targets reduces estimates of strike incentives in bilateral and trilateral configurations with and without defenses by capturing the shift of targeting from military to high value targets at low force levels, which is more important than the details of offenses and defenses in determining strike incentives. The analysis indicates little risk of reduction in bilateral stability in deep offensive force reductions and appropriate defensive deployments.

Inclusion of the shift to high value targets stabilizes trilateral offensive configurations, even when one side's forces are very weak, which differs with the results of analyses based on military costs only. It produces a similar shift when defenses are included, leading to a balance between a strong, defended side and a and weak, undefended side that resembles, on a smaller scale, the balance between the two strong sides. Including the strong, defended side's preference for survival of its high value targets reduces its incentive to strike, which removes the weak side's incentive to preempt. However, that also reduces the strong sides' ability to deter the weaker. The stability of multi-polar configurations are still controlled by that of the least stable dyad, which places constraints on the defenses that can be deployed stably which could be more confining than those from the bilateral balance. 


\section{REFERENCES}

\footnotetext{
${ }^{1}$ G. Canavan, "Missile Defense and Proliferation," A. Zichichi, ed, $25^{\text {th }}$ Session of the International Seminars on Planetary Emergencies, 19-24 August 2000 (London, World Scientific, 2000).

${ }^{2}$ G. Canavan, "Crisis Stability and Strategic Defense" Proceedings of the Military Modeling and Management Session of the ORSA/TIMS National Meeting, November 12-14, S. Erickson, Ed. (Operations Research Society of America: Washington, 1991).

${ }^{3}$ G. Canavan, "Analysis of Decisions in Bi- and Tri-Lateral Engagements," U.S. State Department Stability Workshop (Institute for Defense Analysis, November 2000); Los Alamos National Laboratory Report LAUR-00-5737, November 2000.

${ }^{4}$ G. Kent and R. DeValk, "Strategic Defenses and the Transition to Assured Survival," RAND Report R3369-AF, October, 1986

5 A. Piontkovsky, "Global Defense and Strategic Stability," A. Zichichi, ed, $16^{\text {th }}$ Session of the International Seminars on Planetary Emergencies, 19-24 August 1992 (London, World Scientific, 1993).

${ }^{6}$ R. Powell, Nuclear Deterrence Theory (Cambridge, University Press, 1990).

${ }^{7}$ T. Schelling, The Strategy of Conflict (Cambridge, Mass, Harvard University Press, 1960).

${ }^{8}$ T. Schelling, Arms and Influence (New Haven, Yale University Press, 1966).

${ }^{9}$ G. Canavan, "Analysis of Decisions in Bi- and Tri-Lateral Engagements," op. cit;

${ }^{10}$ G. Kent and R. DeValk, "Strategic Defenses and the Transition to Assured Survival,"

${ }^{11}$ G. Canavan, "Freedom to Mix Defenses in Modest Forces," Los Alamos National Laboratory Report LA-UR-01-4563, June 2001.

${ }^{12}$ G. Canavan, “Analysis of Decisions in Multilateral Engagements,” Los Alamos National Laboratory Report LA-UR-01-1219, February 2001.

${ }^{13}$ G. Canavan, "Considerations in Missile Reductions and De-Alerting," L. Kruger, ed., Missile Proliferation and Defence Seminar 4-9 April 1998 (Erice, World Federation of Scientists, 1998).

${ }^{14}$ G. Canavan, "Cost of Addressing Targets of Unequal Value," Los Alamos National Laboratory Report LA-UR-01-4561, June 2001.

${ }^{15}$ G. Canavan, "Variation of Strike Incentives in Deep Reductions," Los Alamos National Laboratory Report LA-UR-01-4596, June 2001.

${ }^{16}$ G. Canavan, "Variation of Strike Incentives with Damage Preferences," Los Alamos National Laboratory Report LA-UR-01-4597, June 2001.

${ }^{17}$ G. Canavan, "Cost of Addressing Targets of Unequal Value," op. cit.

${ }^{18}$ G. Canavan, "Analysis of Decisions in Bi- and Tri-Lateral Engagements," op. cit.

${ }^{19}$ G. Canavan, "Variation of Strike Incentives with Preference for Survival of High Value Targets," Los Alamos National Laboratory Report LA-UR-01-4590, June 2001.

${ }^{20}$ G. Canavan, "Cost of Addressing Targets of Unequal Value," op. cit.

${ }^{21}$ G. Canavan, "Analysis of Decisions in Bi- and Tri-Lateral Engagements,” op. cit.

${ }^{22}$ G. Canavan, "Limits on Defenses in Interactions Between Disparate Forces," Los Alamos National Laboratory Report LA-UR-01-4598, June 2001.

${ }^{23}$ G. Canavan, "Analysis of Decisions in Multilateral Engagements," $69^{\text {th }}$ Military Operations Research Society Annual Meeting, Annapolis Maryland, 12-14 June 2001 (Alexandria Va, MORSS, 2001); Los Alamos National Laboratory Report LA-UR-01-3115, June 2001.
} 
Fig. 1. Graph for crisis stability decision

$\left(\mathrm{C}_{1}, \mathrm{C}_{2}{ }^{\prime}\right)$

$\left(\mathrm{C}_{1}, \mathrm{C}_{2}{ }^{\prime}\right)$

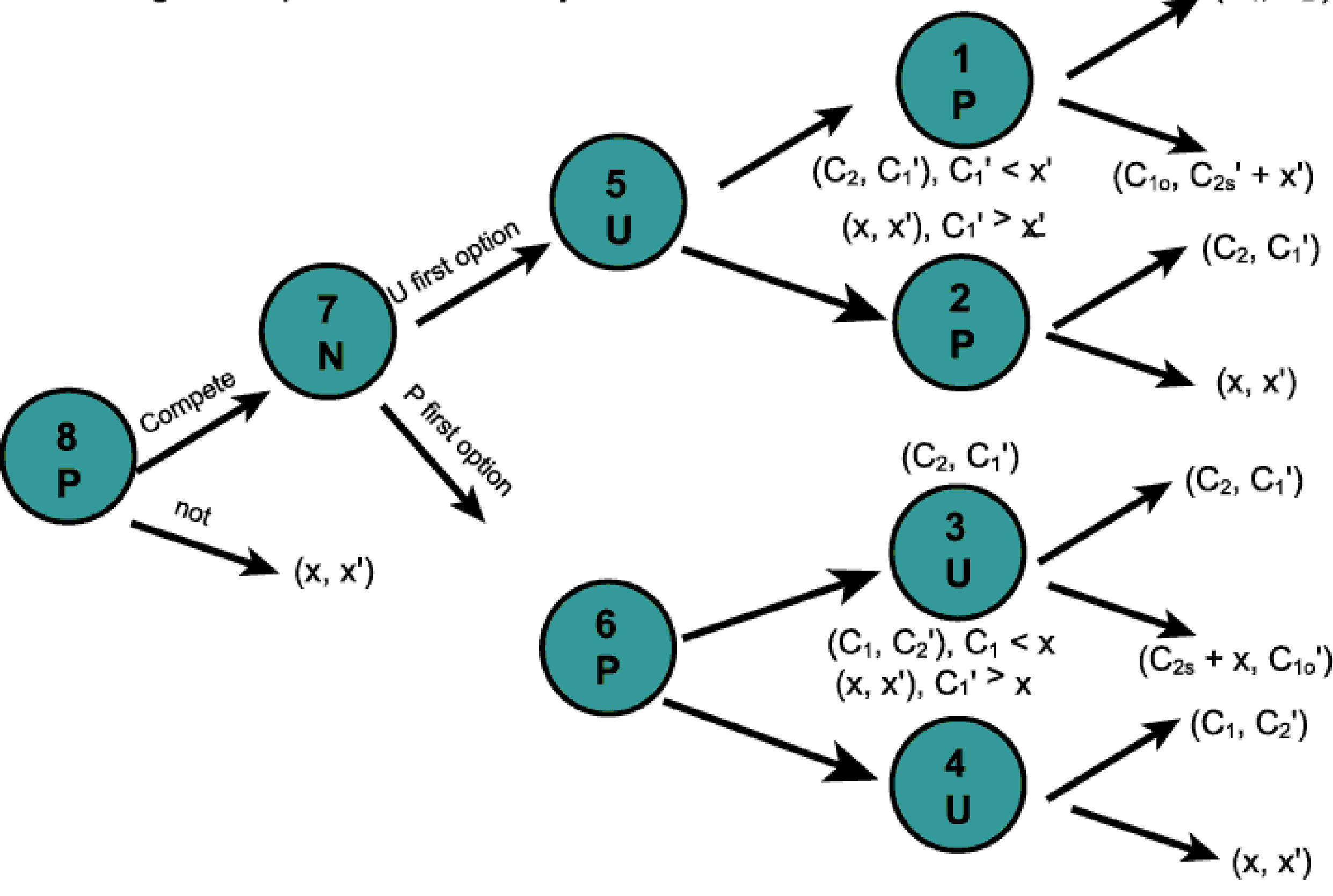


Fig. 2. Cost to $U$ of node u (7U)

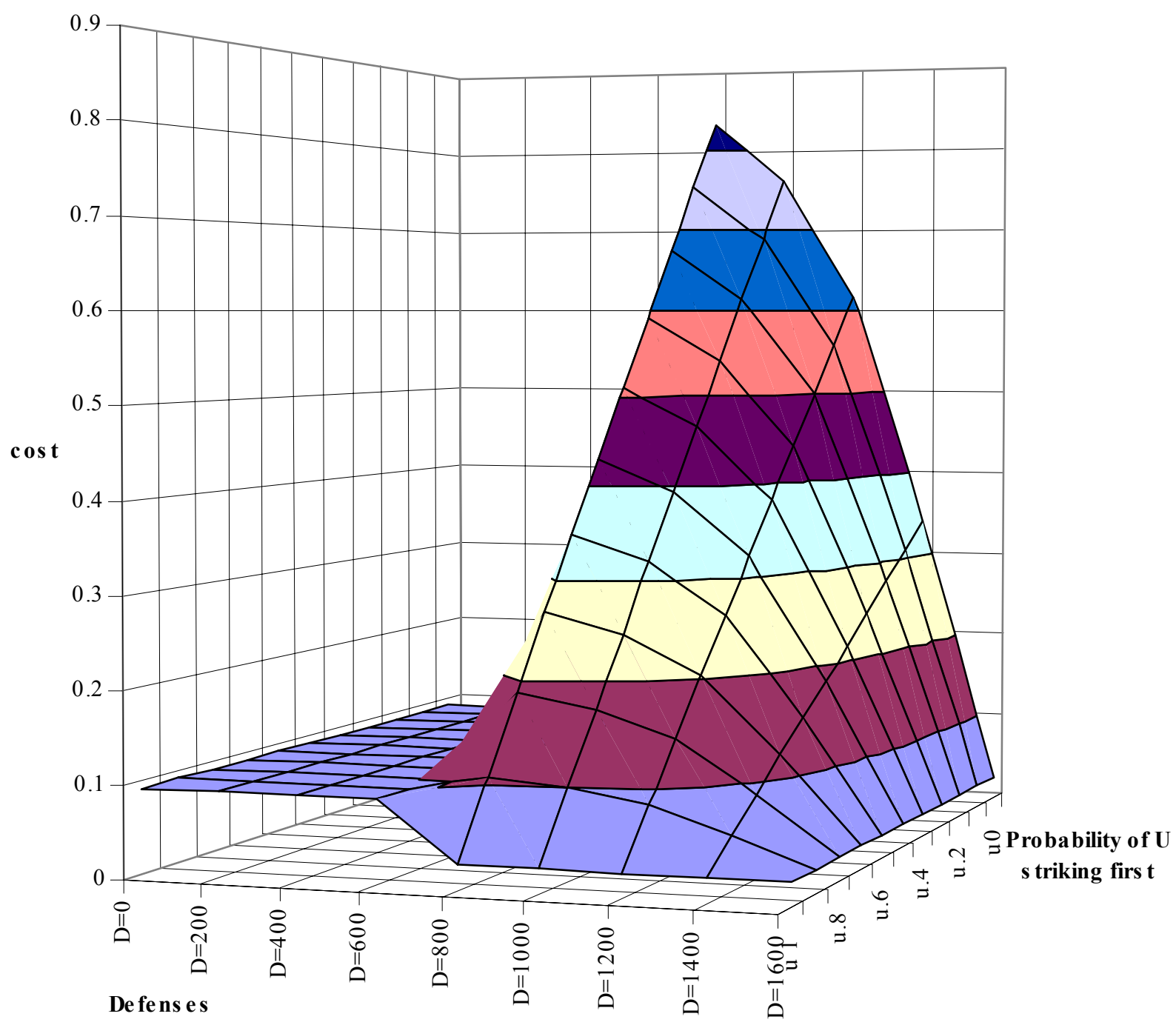


Fig. 3. Indices

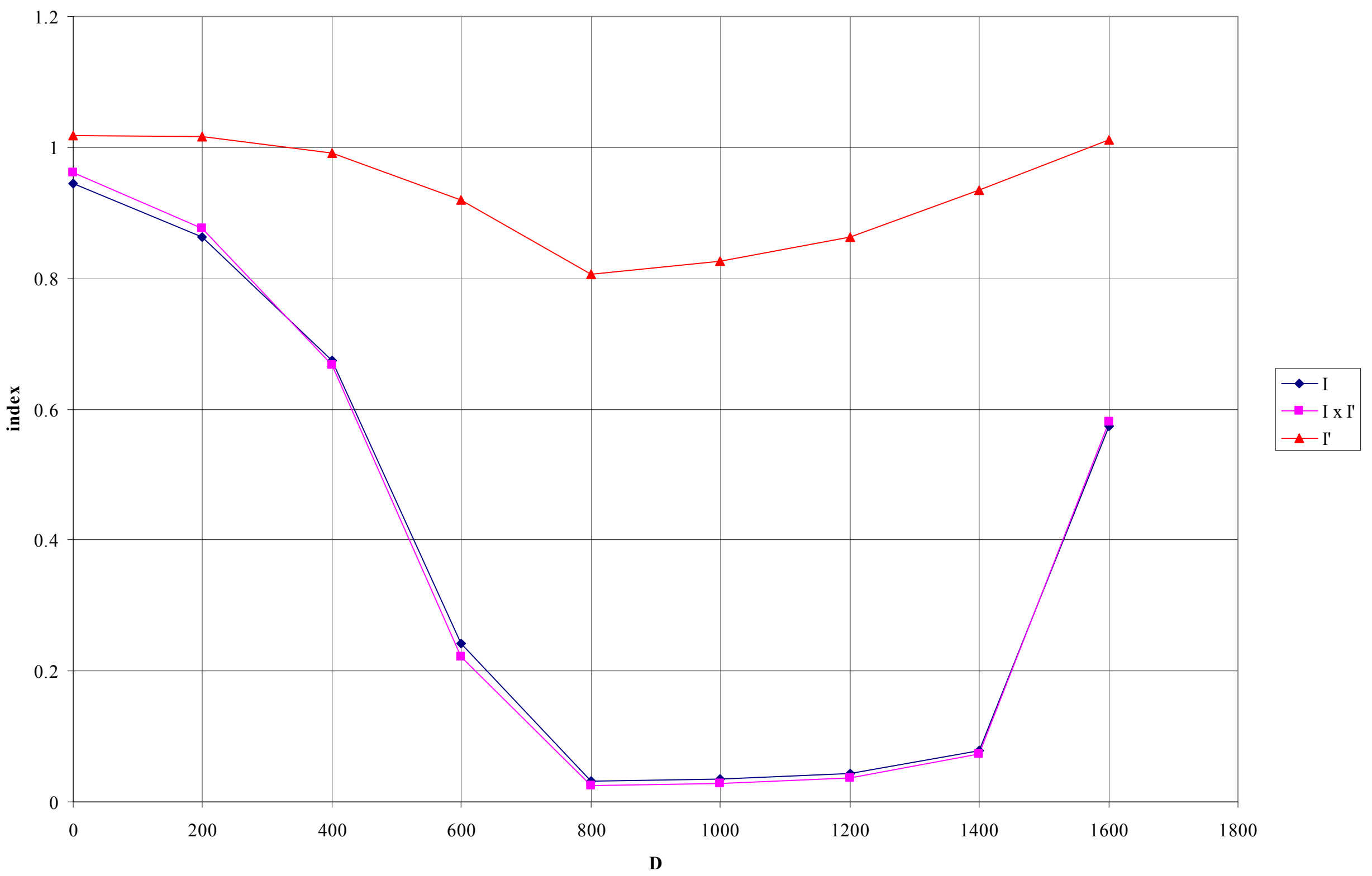


Fig. 4. First strike cost vs weapons with and without defenses

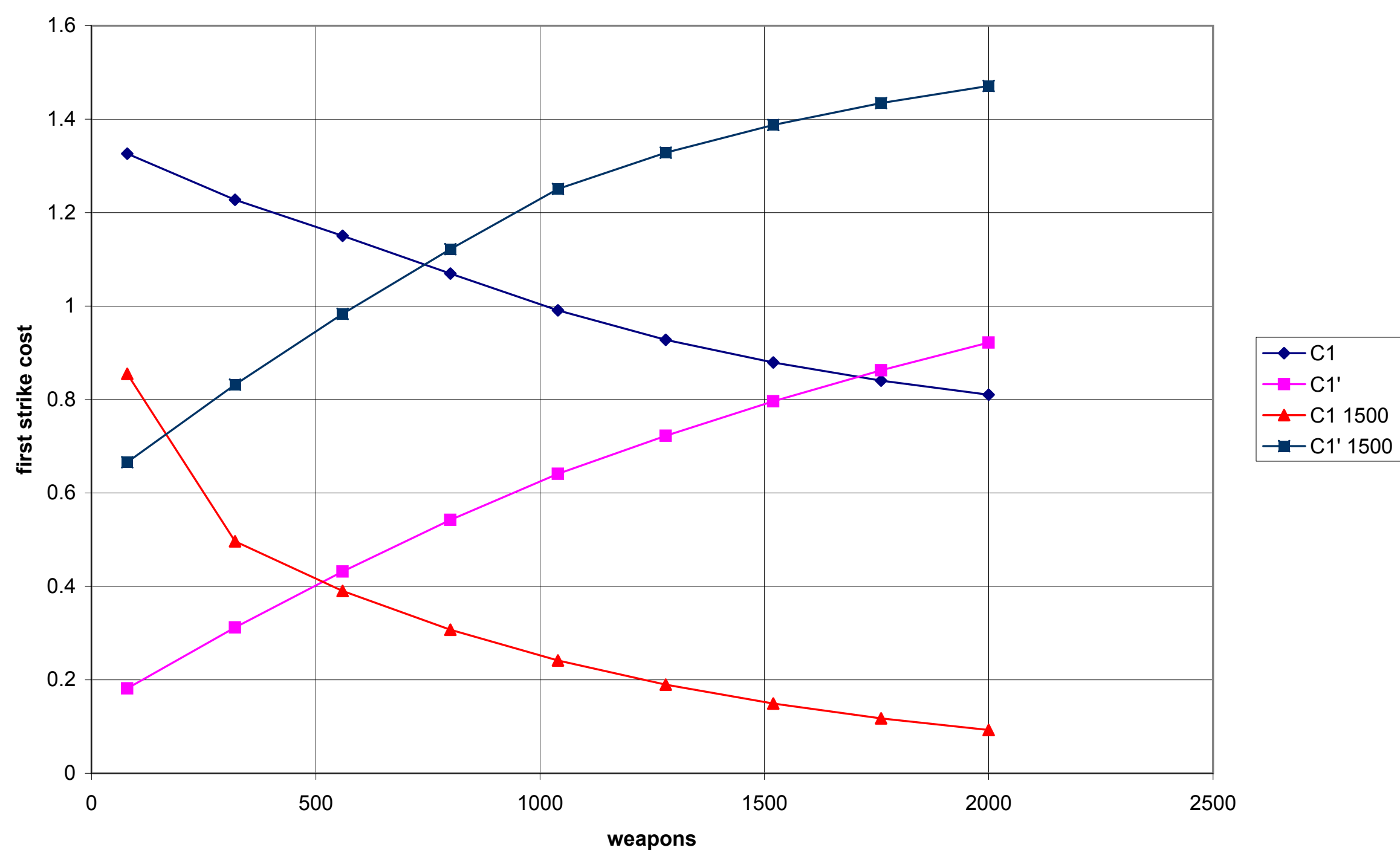


Fig. 5. First strike cost vs $U$ offensive weapons w/ith \& without defenses

$\left(L=L^{\prime}=0.25\right)$

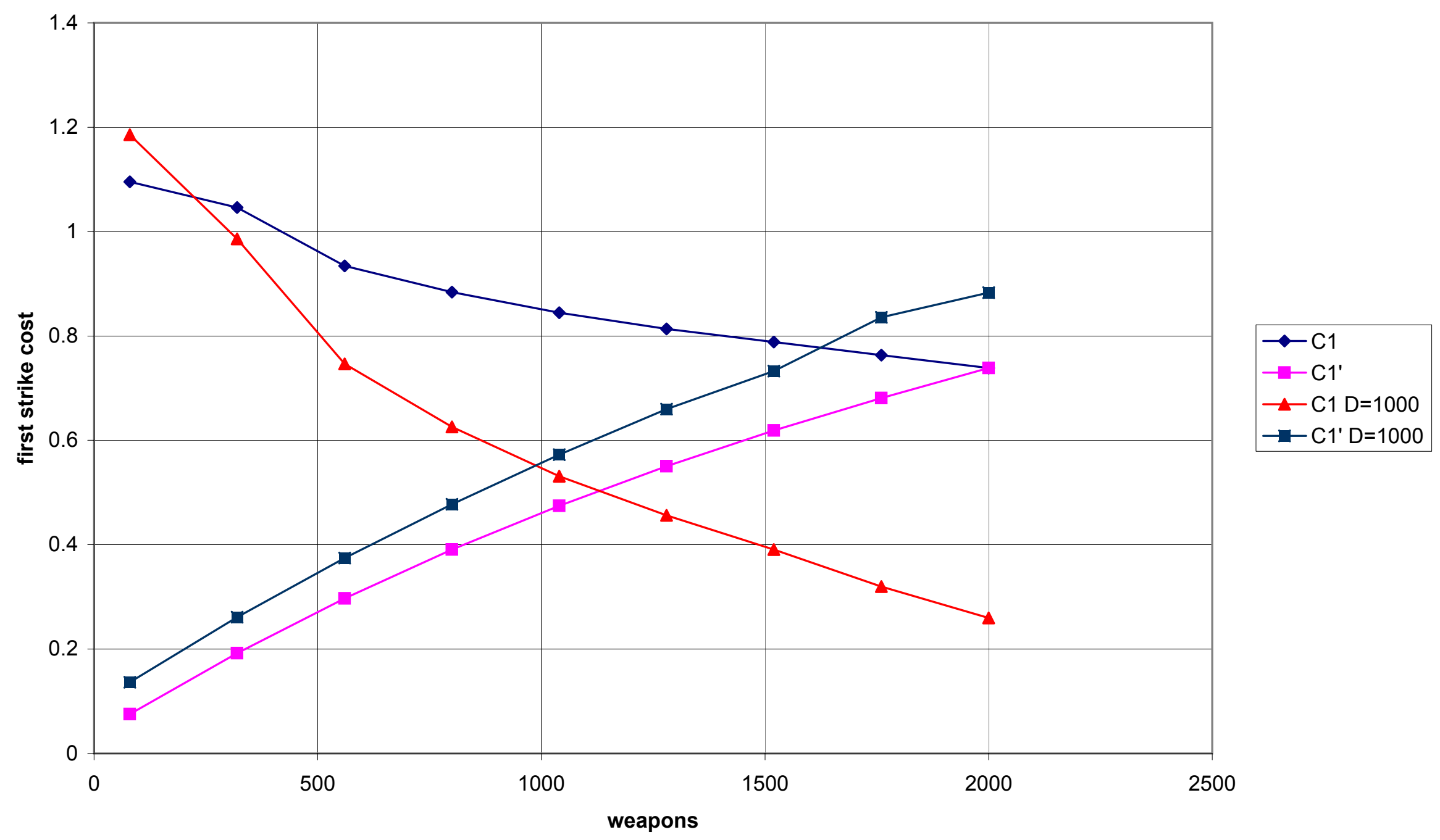


Fig. 6. First and second strikes on military and high value targets as functions of total weapons

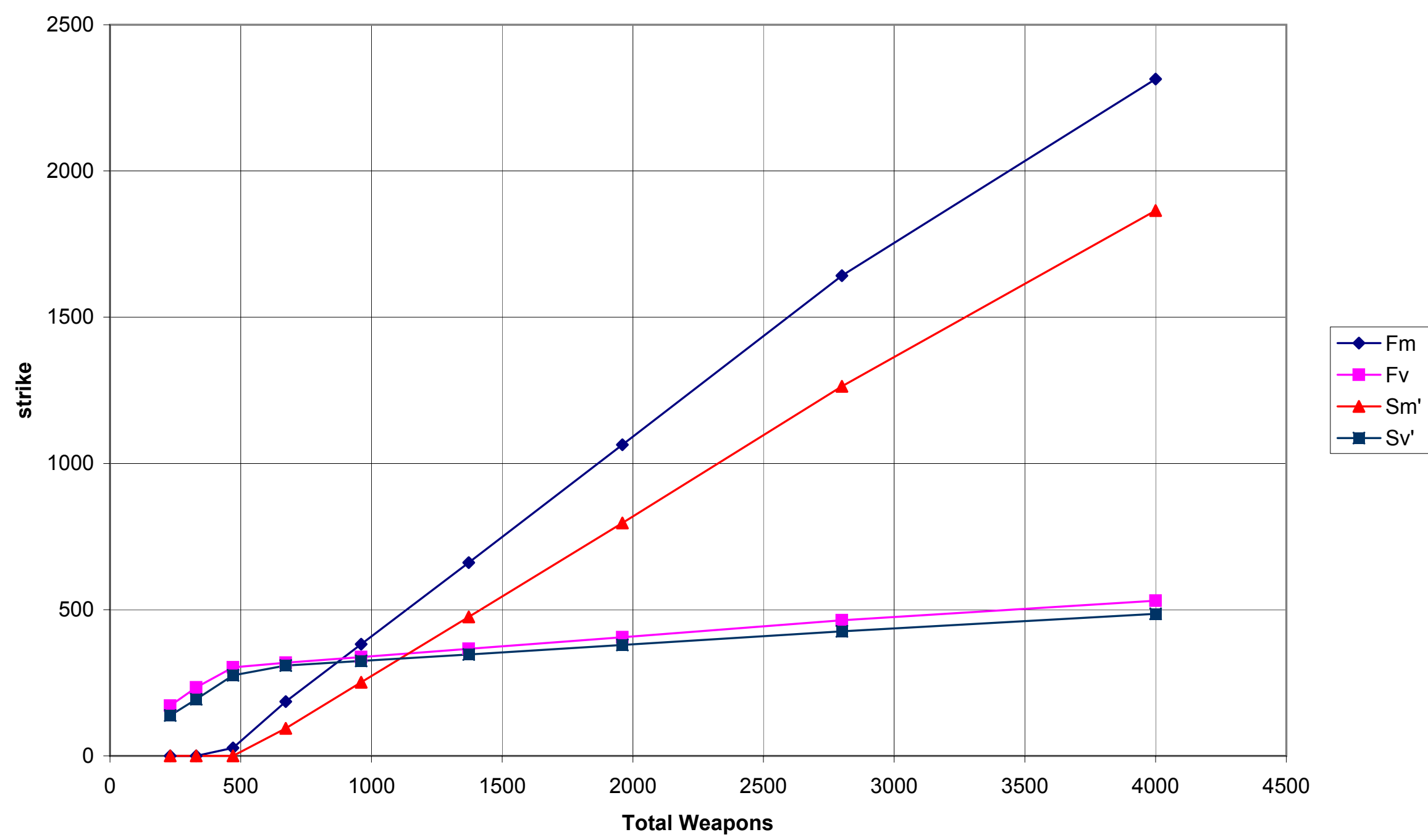


Fig. 7. Costs of nodes $1 \& 2$ as functions of preference for damage to military targets $\left(\mathrm{K}=\mathrm{K}^{\prime}=2 ; \mathrm{V}=\mathrm{V}^{\prime}=1\right)$

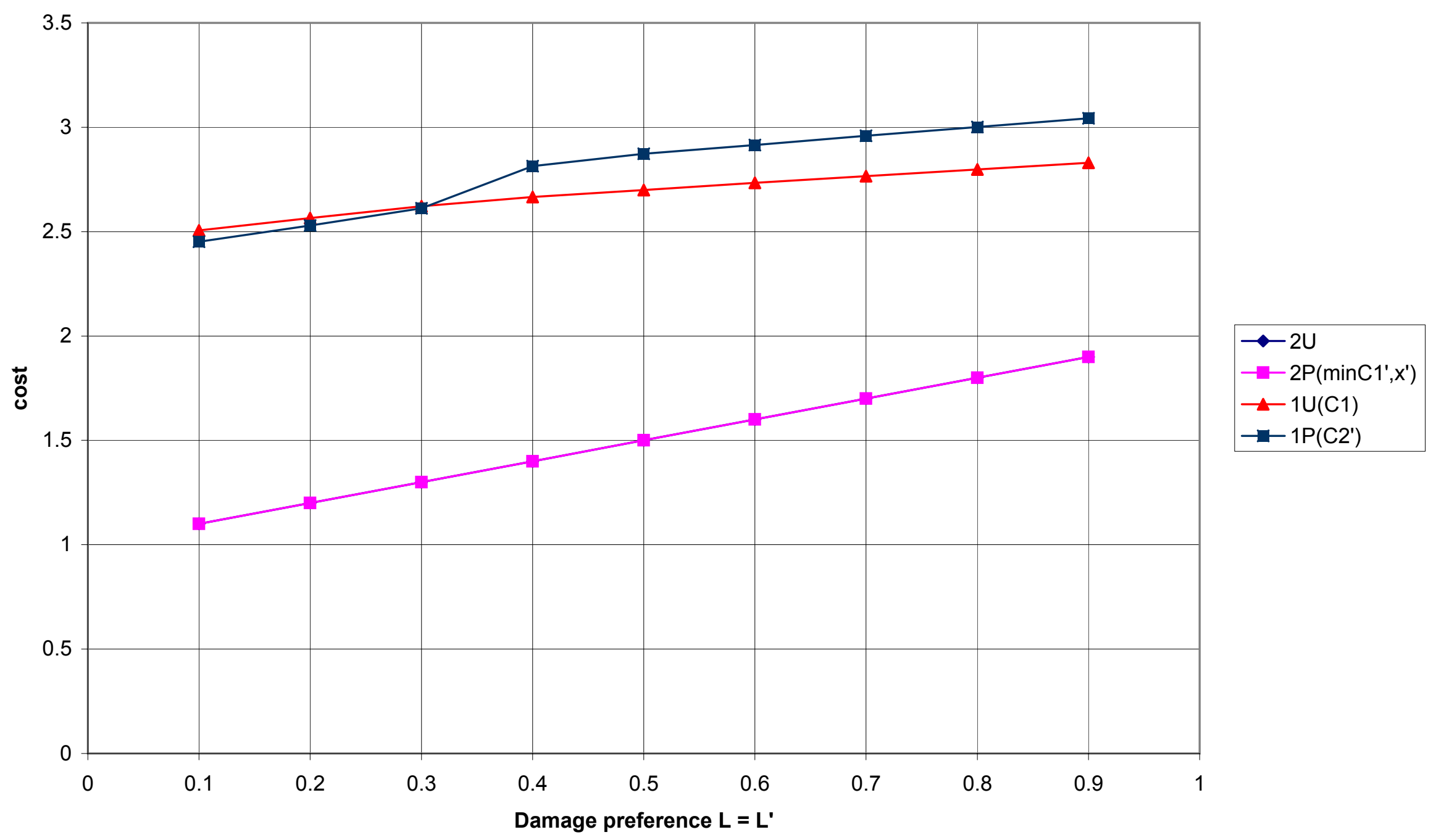


Fig. 8. Costs of node 7 vs preference to protect high value

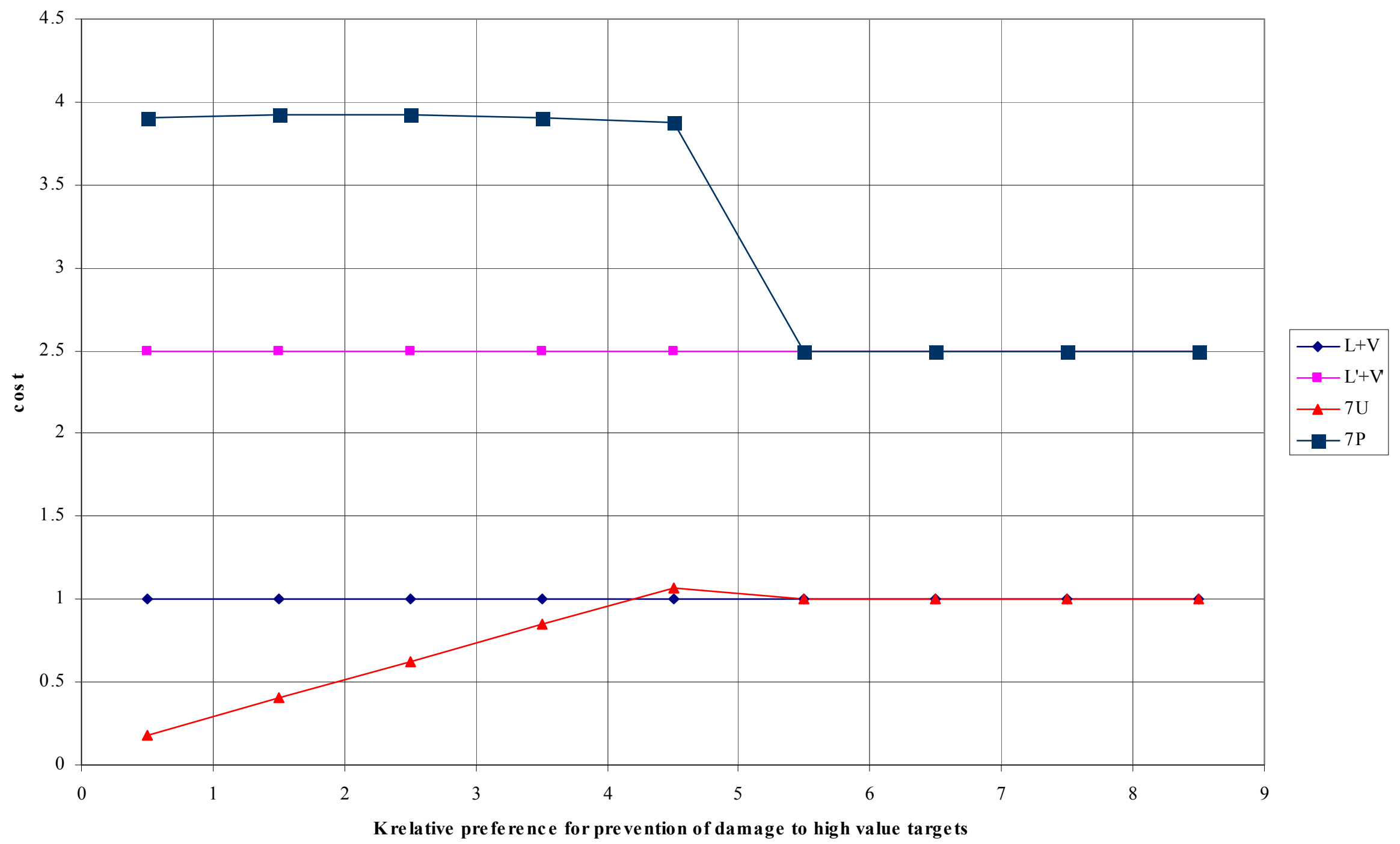


Fig. 9. Cost of node raching node 7 as function of interceptors allocated in tralateral interaction.

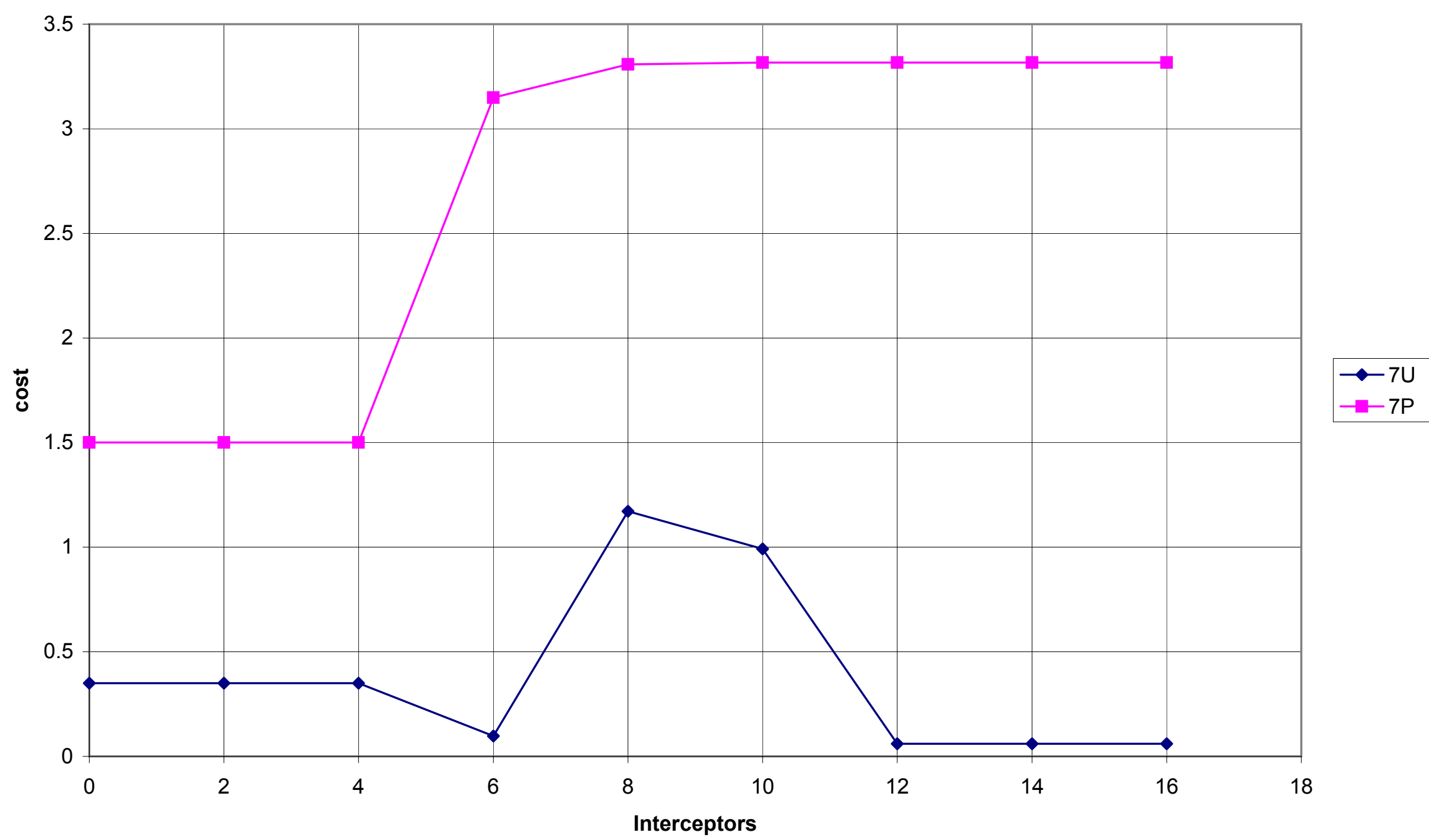




\section{TRANSITION FROM ADVERSARY TO COOPERATIVE INTERACTION}

Gregory H. Canavan

Los Alamos National Laboratory

USA 


\section{Topics}

- Game theory (decision analysis) framework

- Impact of defenses on bilateral stability

- Mixing offenses and defenses

- Impact of reduced deterrence objectives

- Stability at reduced force levels

- Impact on trilateral offensive balances

- Impact on trilateral balances with defenses 


\section{Strikes and Costs}

- First \& second strikes from exchange model

- with optimal allocation between missiles \& value

- Cost = damage to self $+\mathrm{L}(1$-damage to other $)$

- Cost of inaction $=\mathrm{L} \sim$ damage to deter, compel

- First striker minimizes $\mathrm{C}_{1}$

- Decision to strike based on minimum $\left(\mathrm{C}_{1}, \mathrm{~L}\right)$

- Side struck receives 2nd strike $\operatorname{cost} \mathrm{C}_{2}$ 


\section{Game Theory Essentials}

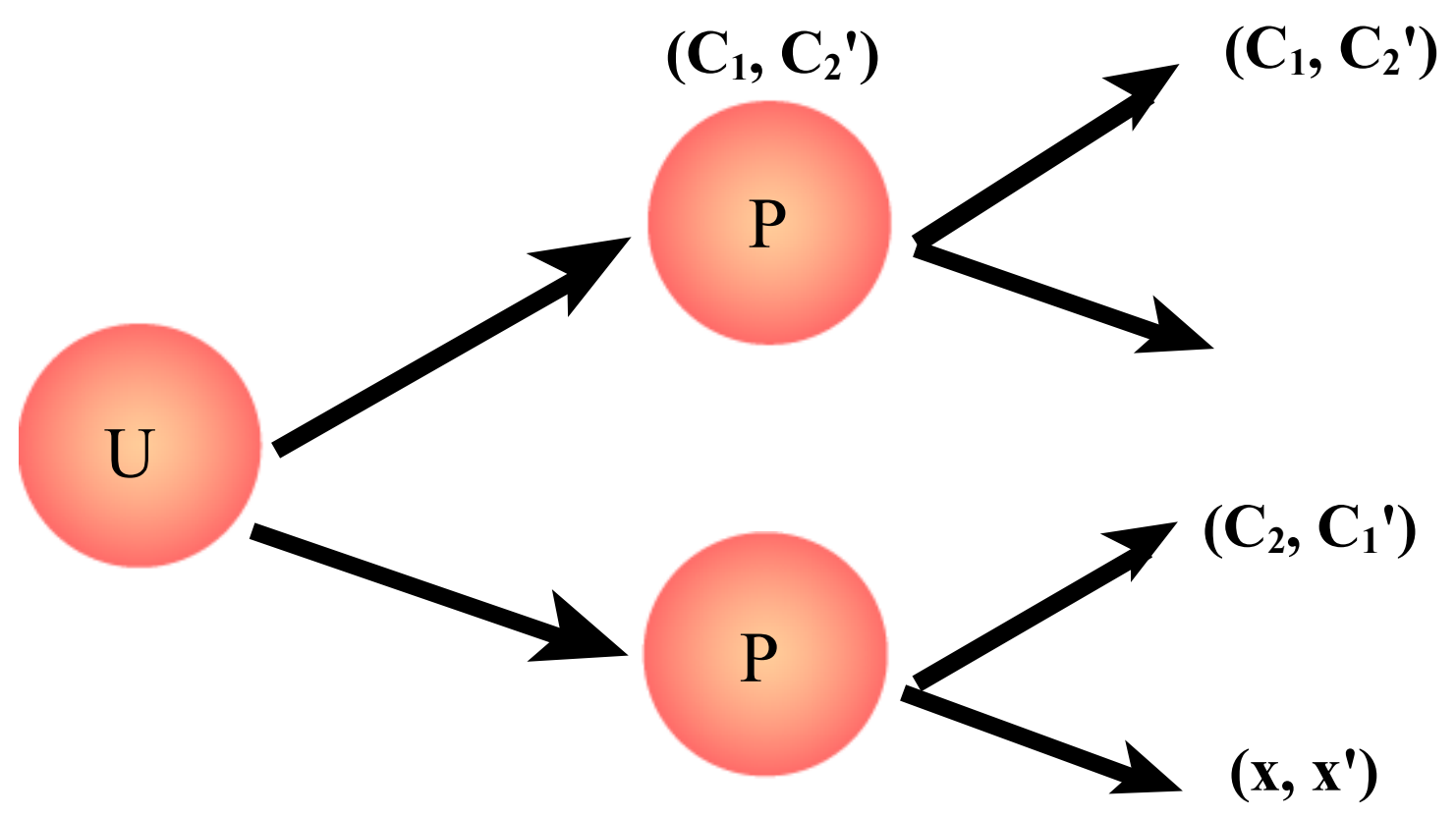


Fig. 5. cost of nodes $1 \& 2$ vs m' (U first option)

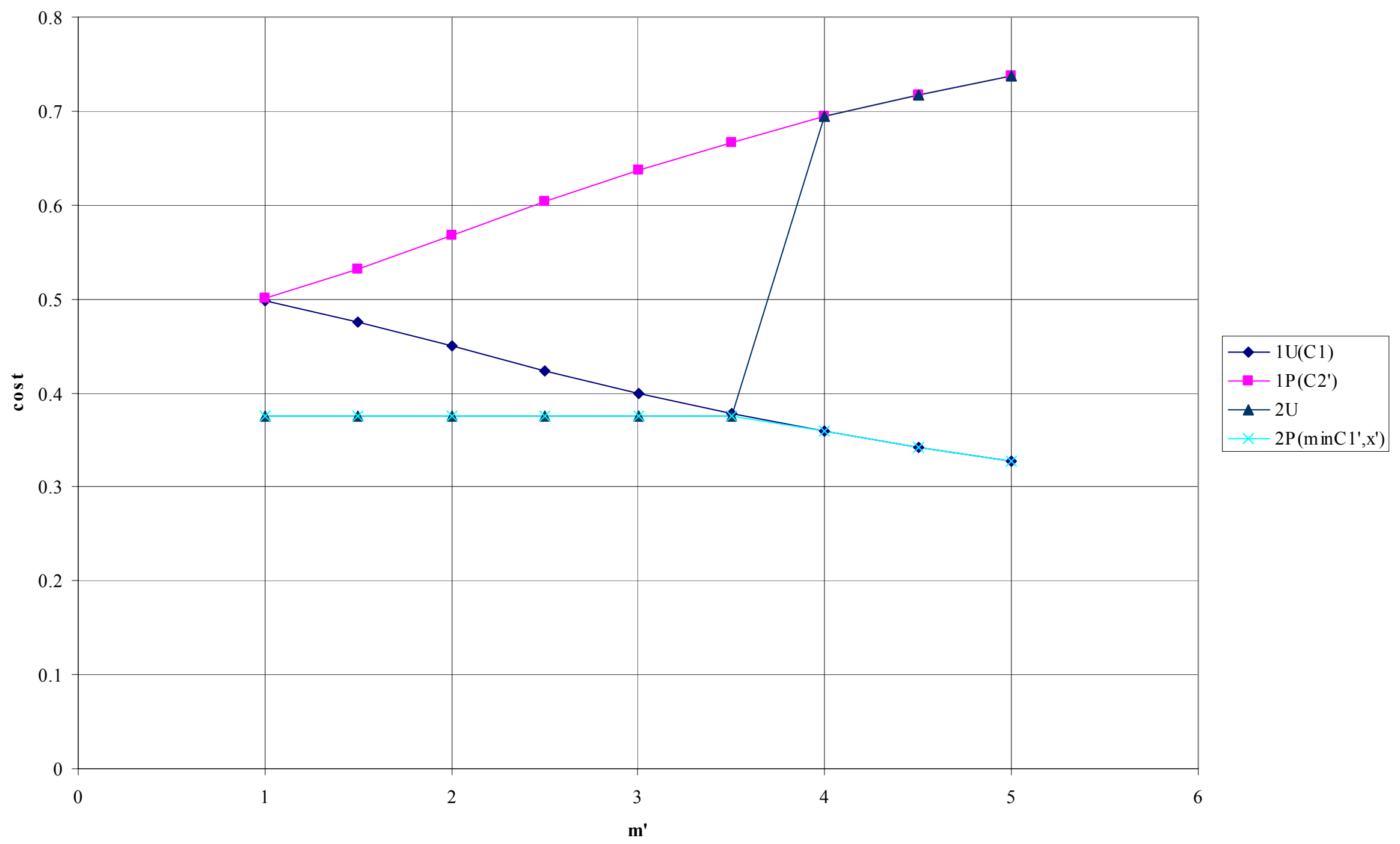




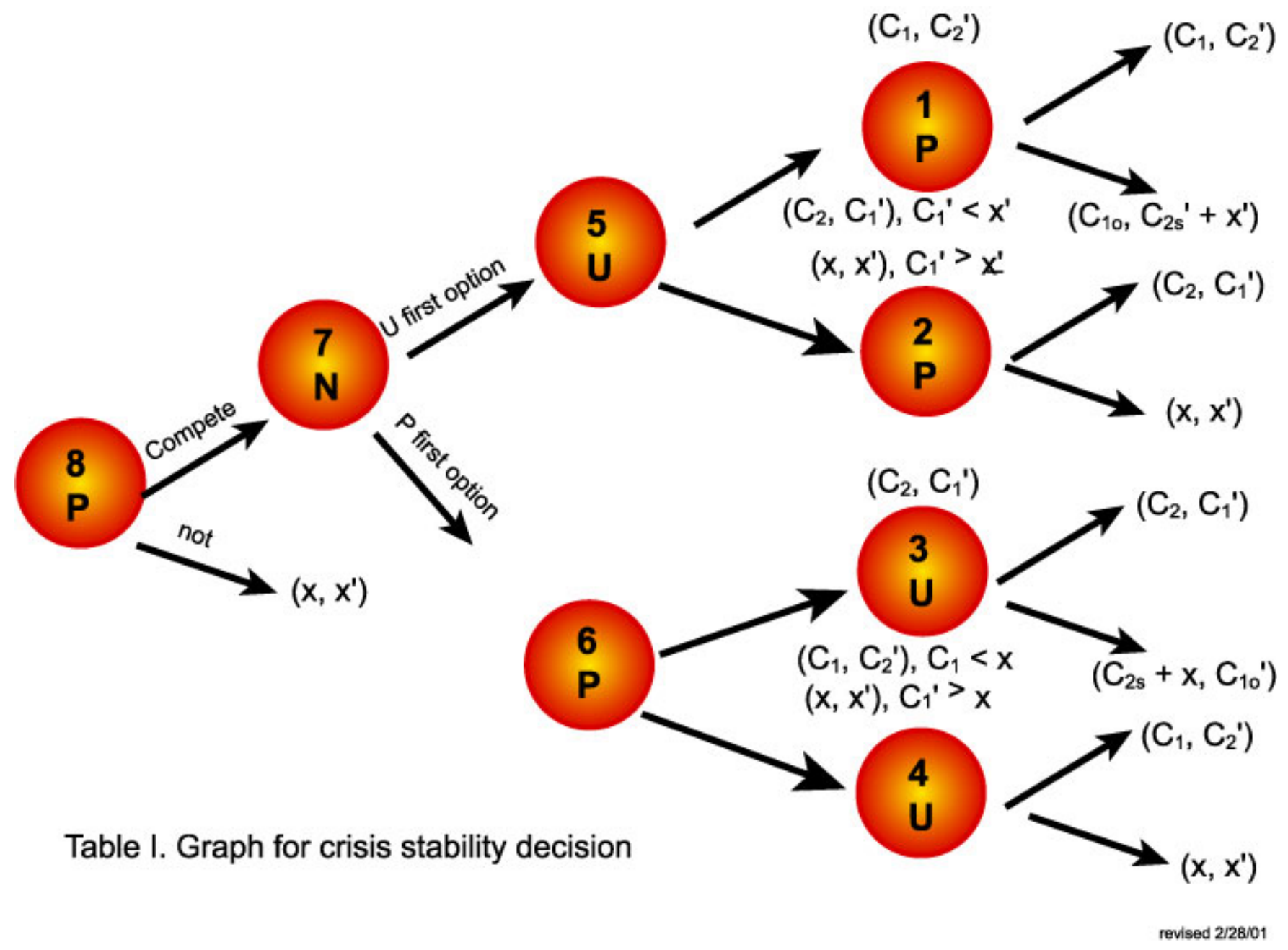




\section{Bilateral Engagements w/ Defenses}

- U \& P at START I offensive force levels

- Add ideal midcourse or boost phase defenses

- U trade offenses for defenses

- Compare with predictions of cost ratio metric 
Fig. 14. Cost to $U$ of node u (7U)

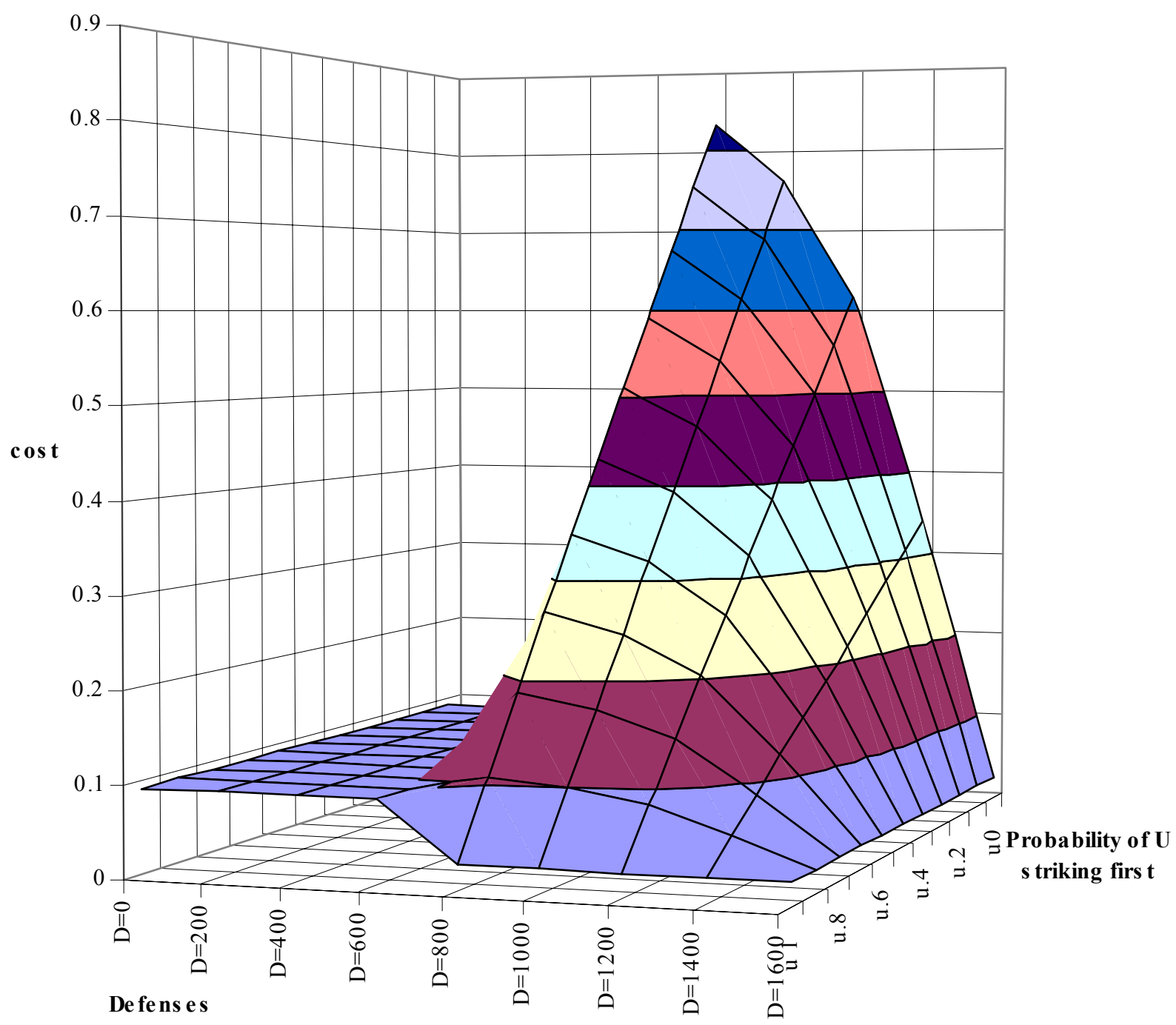


First strike cost vs weapons w/ \& w/o defenses

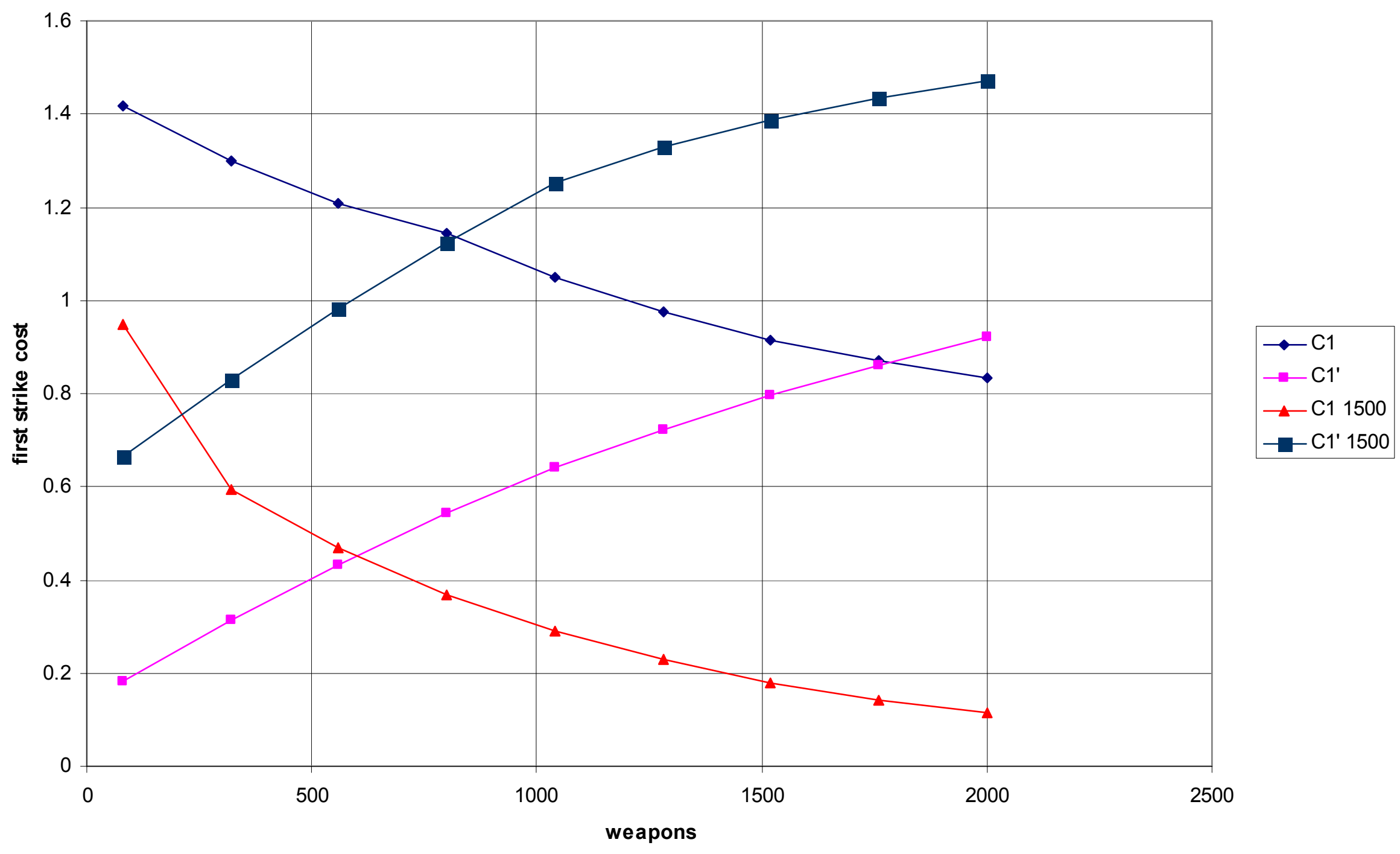




\section{First strike cost vs weapons w/ \& w/o defenses}

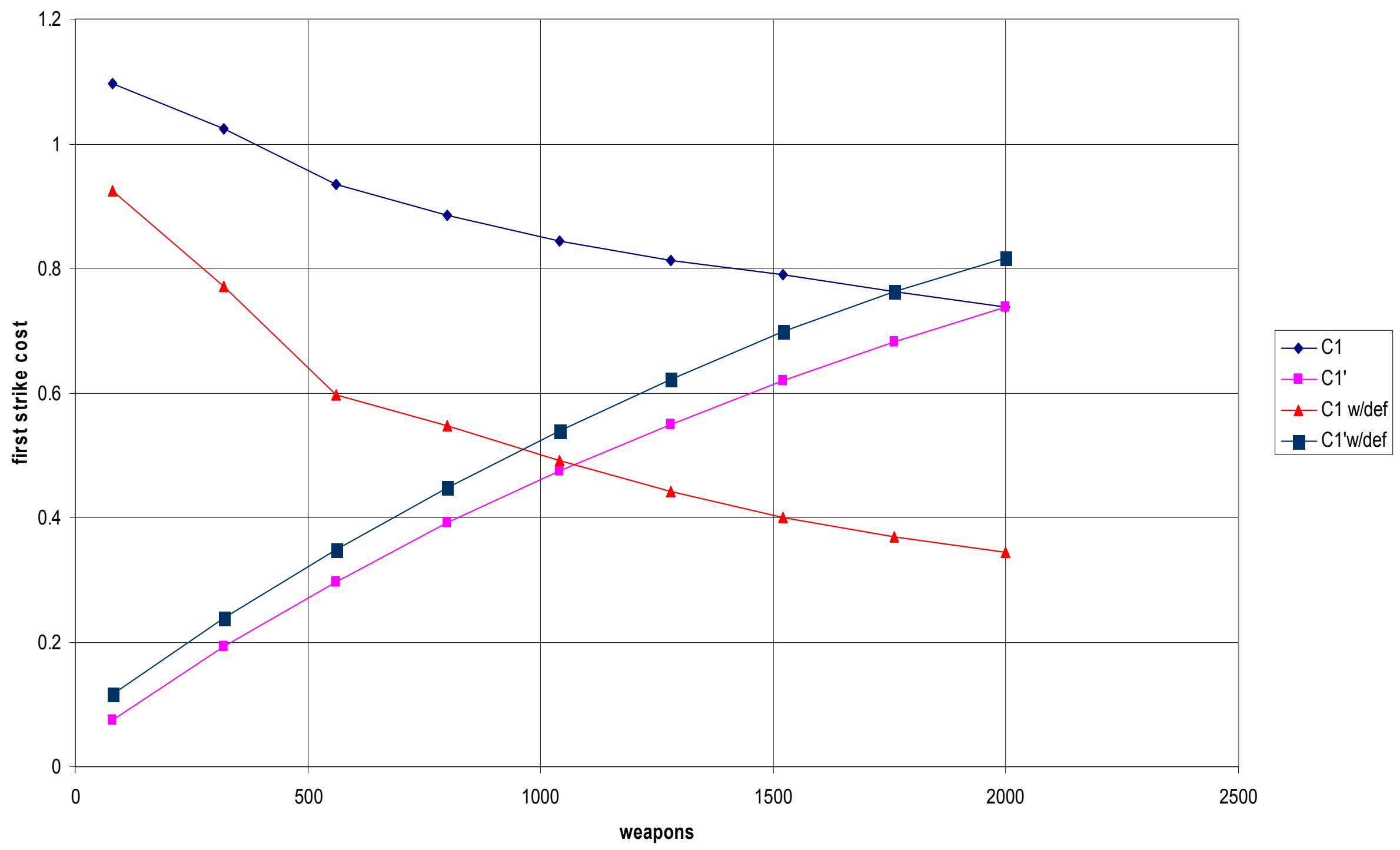


Fig. 8. Indices

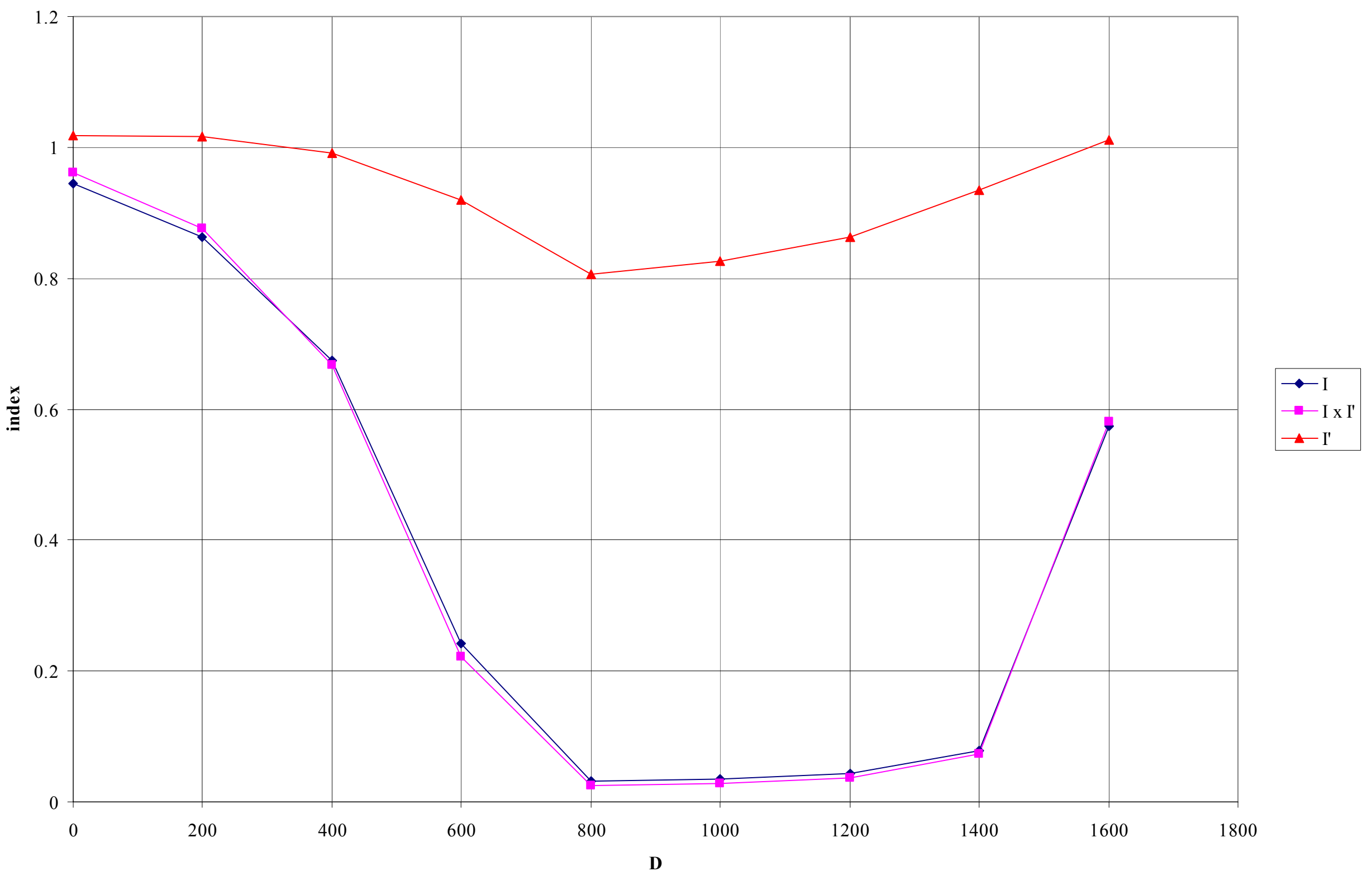




\section{Bilateral Interactions w/ Defenses Observations}

- Moderate defenses do not increase strike incentives (i.e, do not impact stability)

- Undefended side sees an incentive to preempt at some level of defenses

- Can deploy significant defenses stably

- trade offense for defense at constant 1st strike costs

- reduce deterrence objectives 


\section{Bilateral Offensive Engagements}

- Strike incentives at low force levels

- Role of high value targets

- Reduced deterrence objectives

- Impact of valuation of high value targets 
Table II. Vulnerable and survivable missiles and weapons

\begin{tabular}{|r|l|c|r|c|c|c|c|c|c|c|r|}
\hline pd. & regime & $\mathrm{m}$ & $\mathrm{M}$ & $\mathrm{n}$ & $\mathrm{N}$ & $\mathrm{W}$ & $\mathrm{m}^{\prime}$ & $\mathrm{M}^{\prime}$ & $\mathrm{n}^{\prime}$ & $\mathrm{N}^{\prime}$ & $\mathrm{W}^{\prime}$ \\
\hline 1 & SALT II & 2.5 & 1000 & 8.6 & 672 & 8229 & 4.7 & 1400 & 3 & 940 & 9400 \\
\hline 2 & START I 1 & 3.2 & 960 & 8.2 & 528 & 7363 & 5.6 & 1090 & 3.5 & 728 & 8652 \\
\hline 3 & START I 2 & 3.2 & 755 & 8.1 & 480 & 6304 & 5.2 & 880 & 3.8 & 664 & 7099 \\
\hline 4 & START I 3 & 2 & 750 & 8 & 450 & 5100 & 3 & 880 & 3.8 & 660 & 5148 \\
\hline 5 & START II 1 & 1 & 500 & 8 & 375 & 3500 & 3 & 500 & 4 & 500 & 3500 \\
\hline 6 & START II 2 & 1 & 500 & 5 & 336 & 2180 & 1 & 500 & 5 & 450 & 2750 \\
\hline 7 & START III & 1 & 200 & 4 & 336 & 1544 & 1 & 200 & 4 & 300 & 1400 \\
\hline 8 & NAS 1 & 1 & 160 & 3.5 & 240 & 1000 & 1 & 160 & 3.5 & 240 & 1000 \\
\hline 9 & NAS 2 & 1 & 60 & 1 & 240 & 300 & 1 & 60 & 1 & 240 & 300 \\
\hline
\end{tabular}


First and second s trike cos ts $\mathrm{C} 1 \& \mathrm{C} 2$

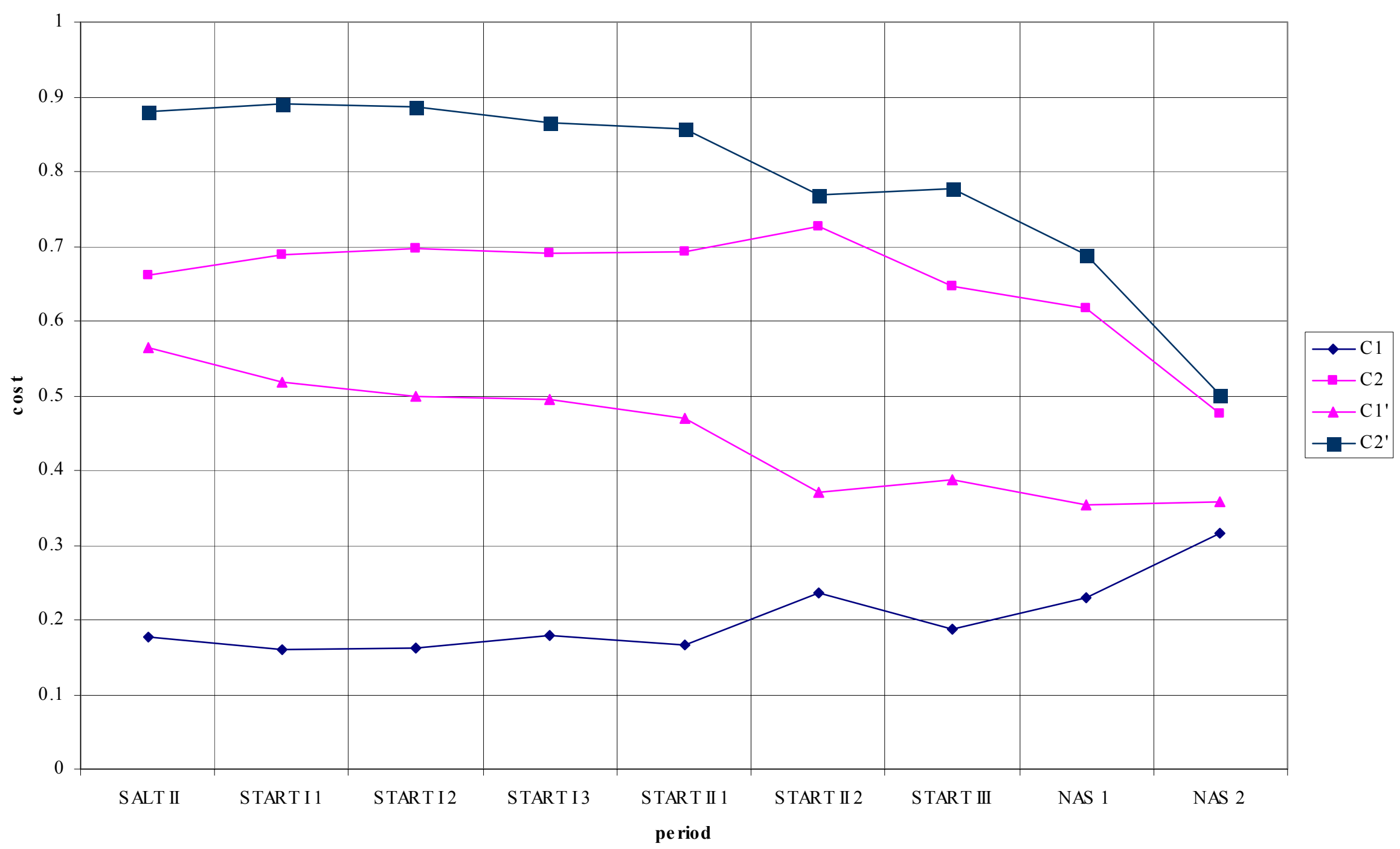




\section{First Strike Cost for Targets of Unequal Value}

- $\mathrm{C}_{1}=$ military + high value $=\mathrm{C}_{1 \mathrm{~m}}+\mathrm{C}_{1 \mathrm{v}}$ Cost $=$ self $+\underline{\text { other }}$

- military value $\left(1-\mathrm{e}^{-\mathrm{kg}^{\prime} \mathrm{S}^{\prime}}\right)+\mathrm{Le}^{-\mathrm{k}^{\prime} \mathrm{hF}}$

- high value $+\mathrm{K}\left(1-\mathrm{e}^{-\mathrm{v}\left(1-\mathrm{g}^{\prime}\right) \mathrm{S}^{\prime}}\right)+\mathrm{Ve}^{-\mathrm{v}^{\prime}(1-\mathrm{h}) \mathrm{F}}$

- $\mathrm{K}=\mathrm{U}$ 's preference survival its high value $-\mathrm{g}^{\prime}=\%$ P's 2nd strike on U military

- $\mathrm{V}=\mathrm{U}$ 's preference for attack on P high value $-\mathrm{h}=\% \mathrm{U} 1$ st strike on P military 
costs vs opponent's preference for attacking military value

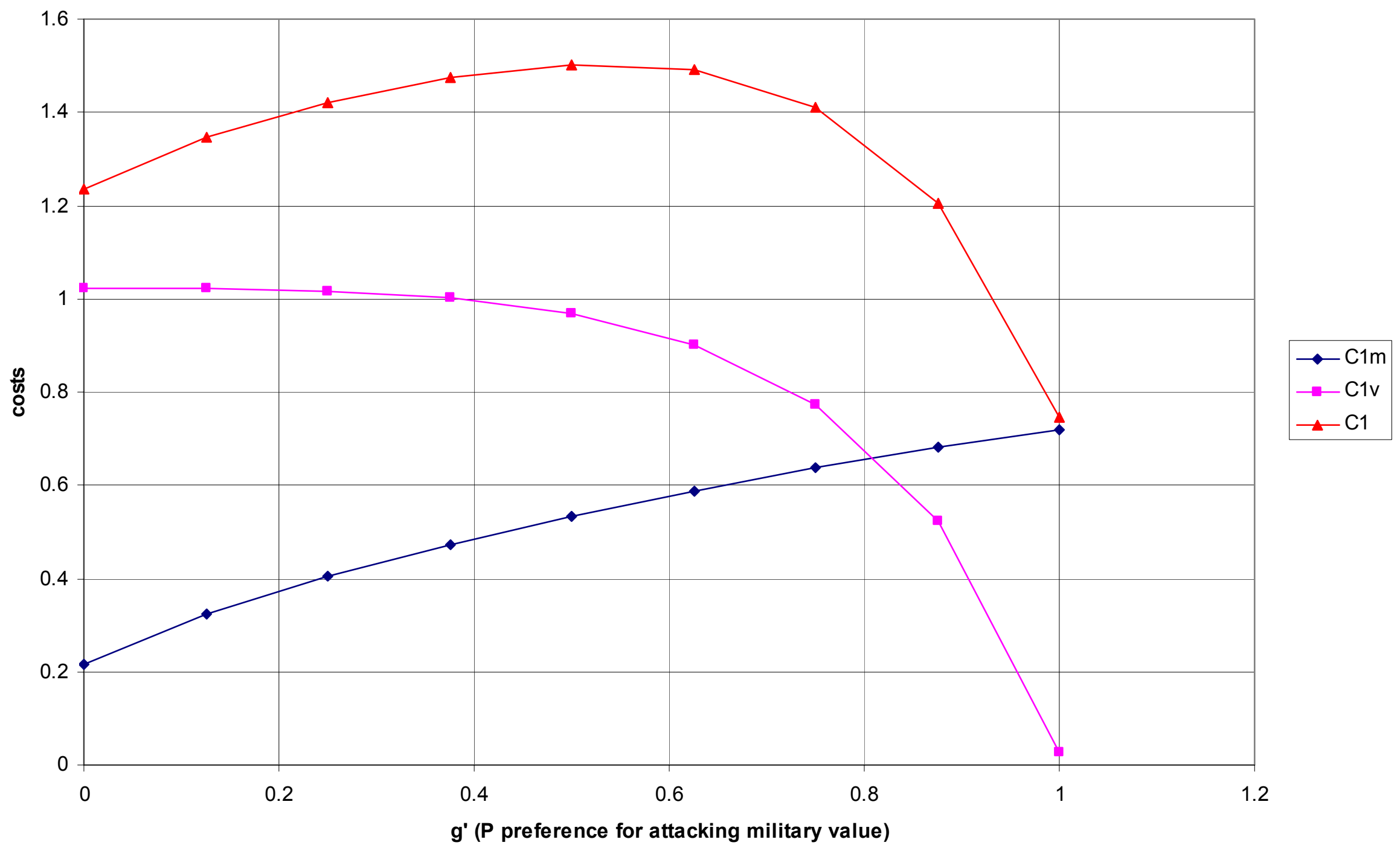


U strikes first

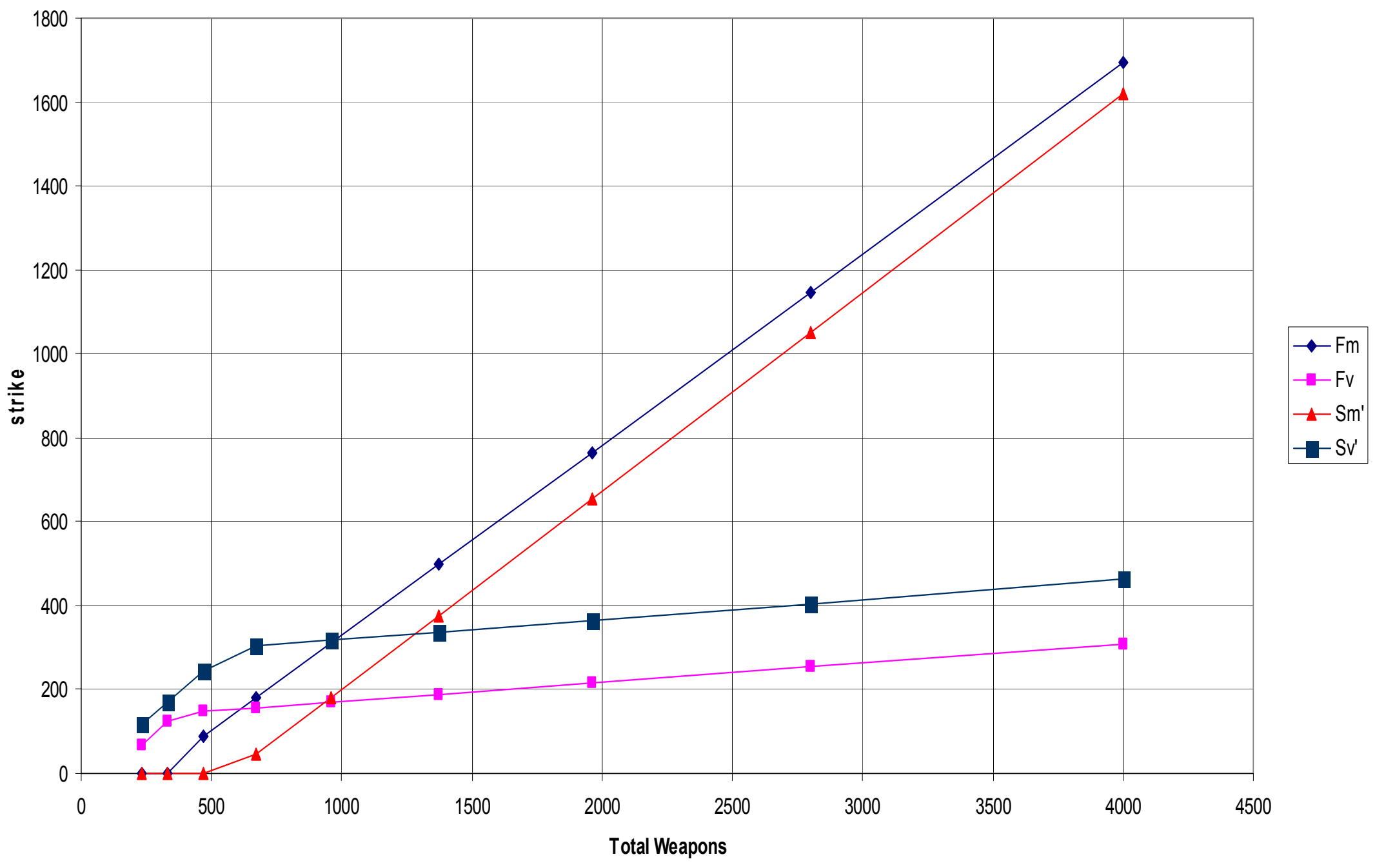


Costs of nodes $1 \& 2$

(K=K'=2; V=V'=1)

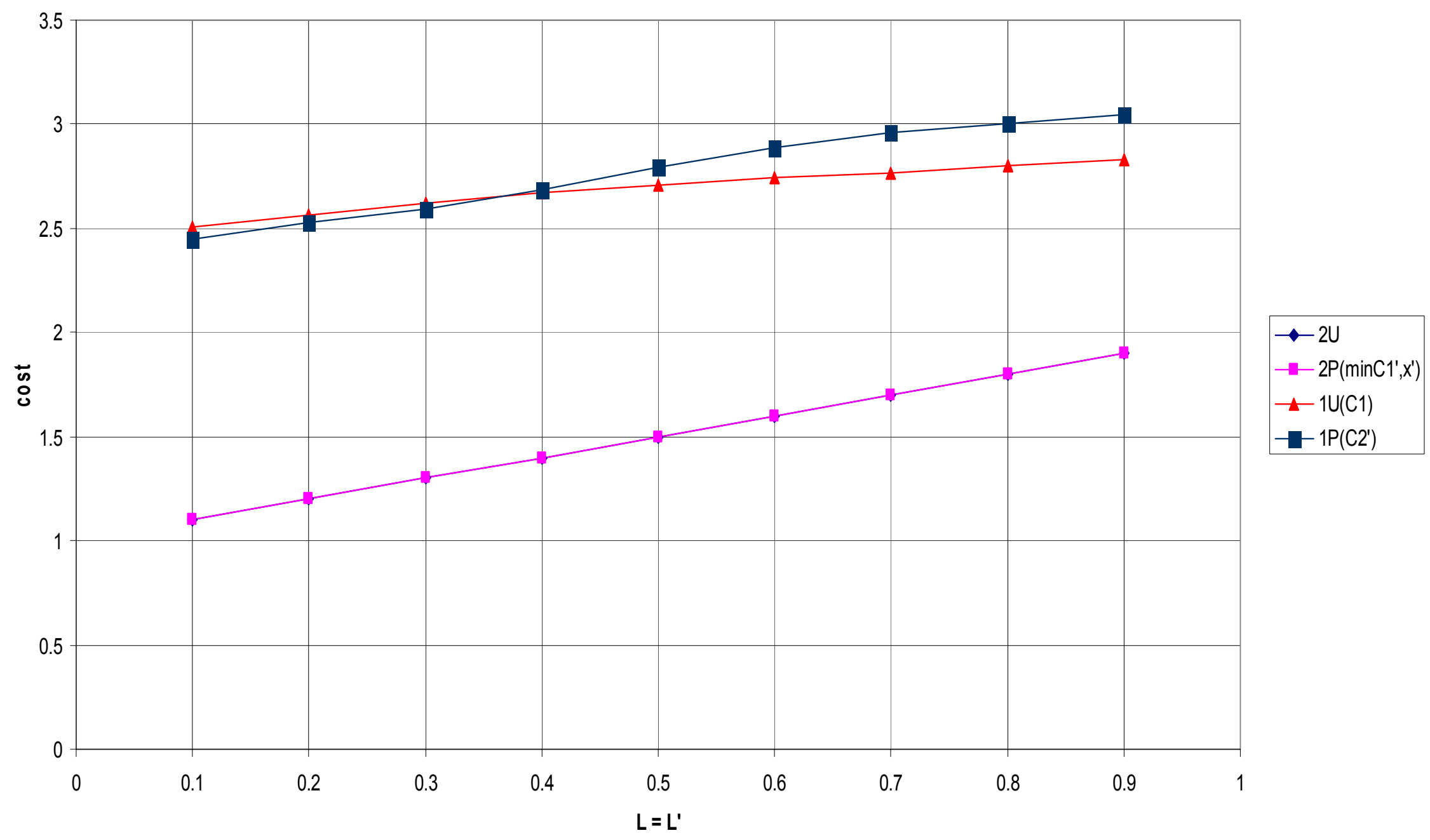


Fig.7. costs vs 1 st strike high value parameter $V$

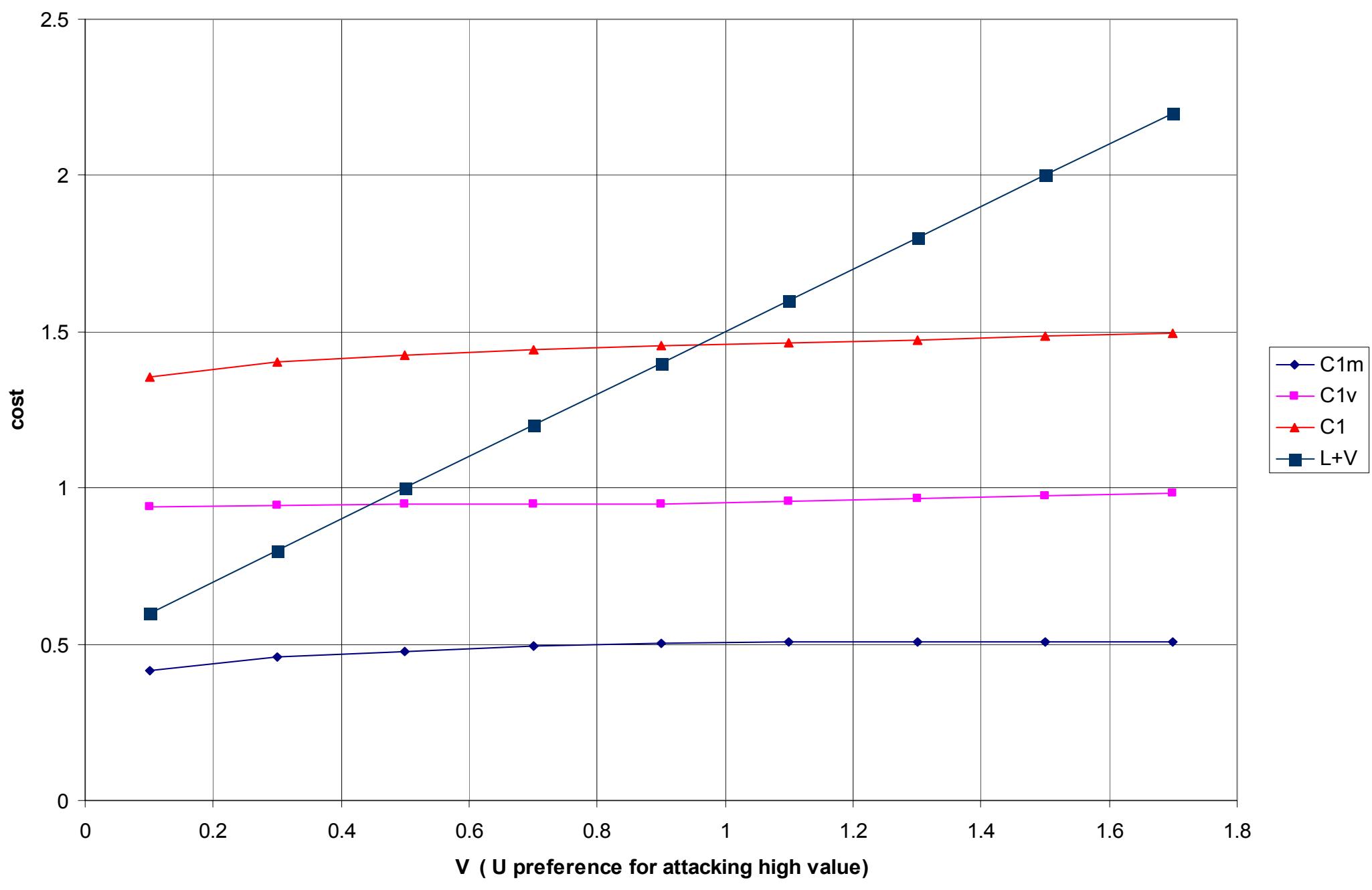


Fig. 9. cost vs 2 nd strike high value parameter $K$

$W=1,000$ weapons

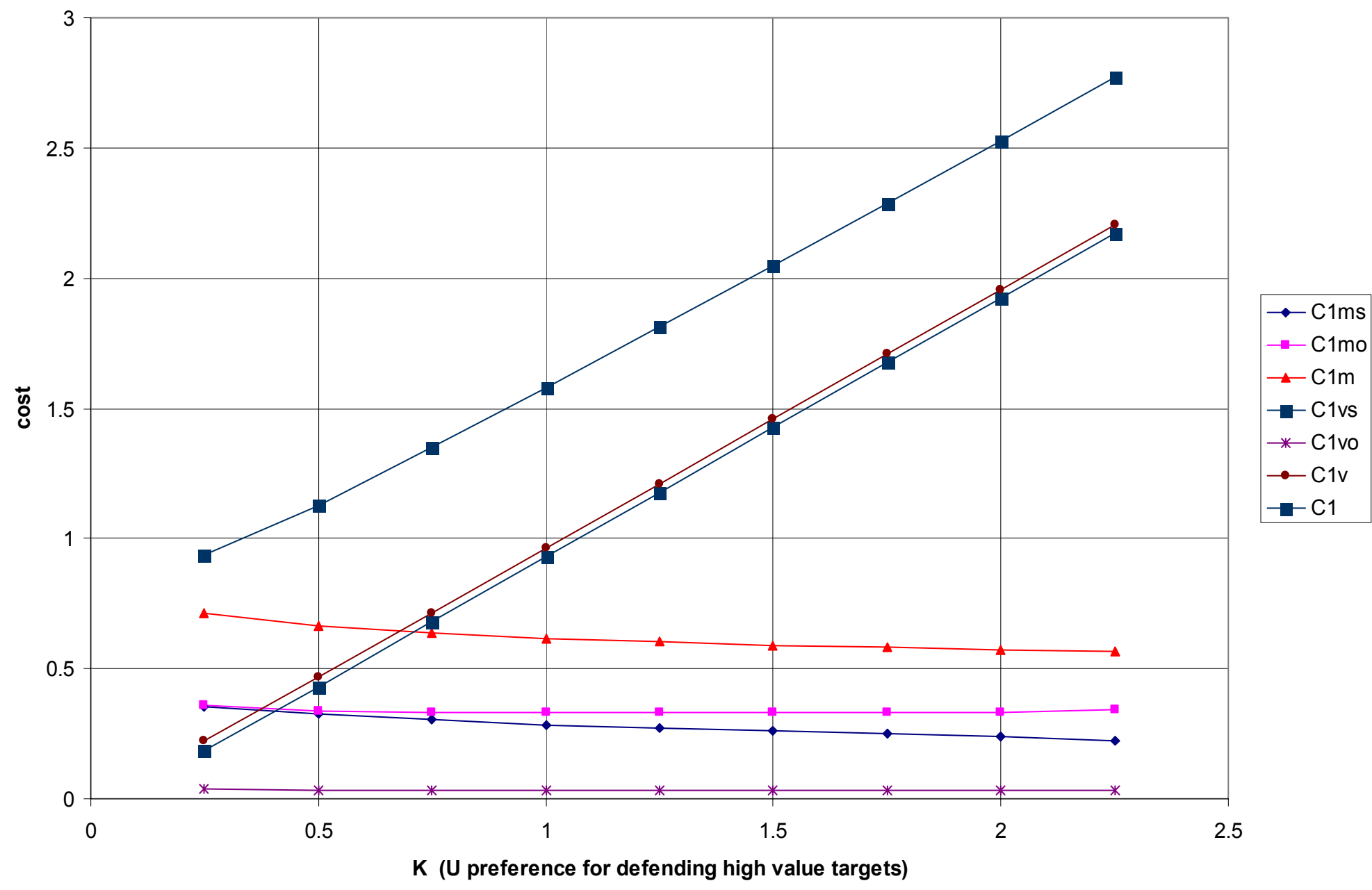




\section{Bilateral Strategic Observations}

- First strike incentive offset by uncertainty over which side could strike first in crisis

- At lower forces, attacks shift to higher value targets

- Transition at $\sim 1,000$ weapons

- Increases strike cost, not incentives

- Strongly stable all L for comparable offensive forces

- Strike incentives

- Increase $\mathrm{w} /$ preference to attack high value

- Decrease w/ preference to defend high value 


\section{Trilateral Offensive Engagements}

- U \& P at current force levels

- P offenses vary current to START

- Optimize U-P \& U-T interactions using

- Military targets only

- Military \& high value 
Fig. 14. Cost of nodes $3 \& 4$ for $U \& T$

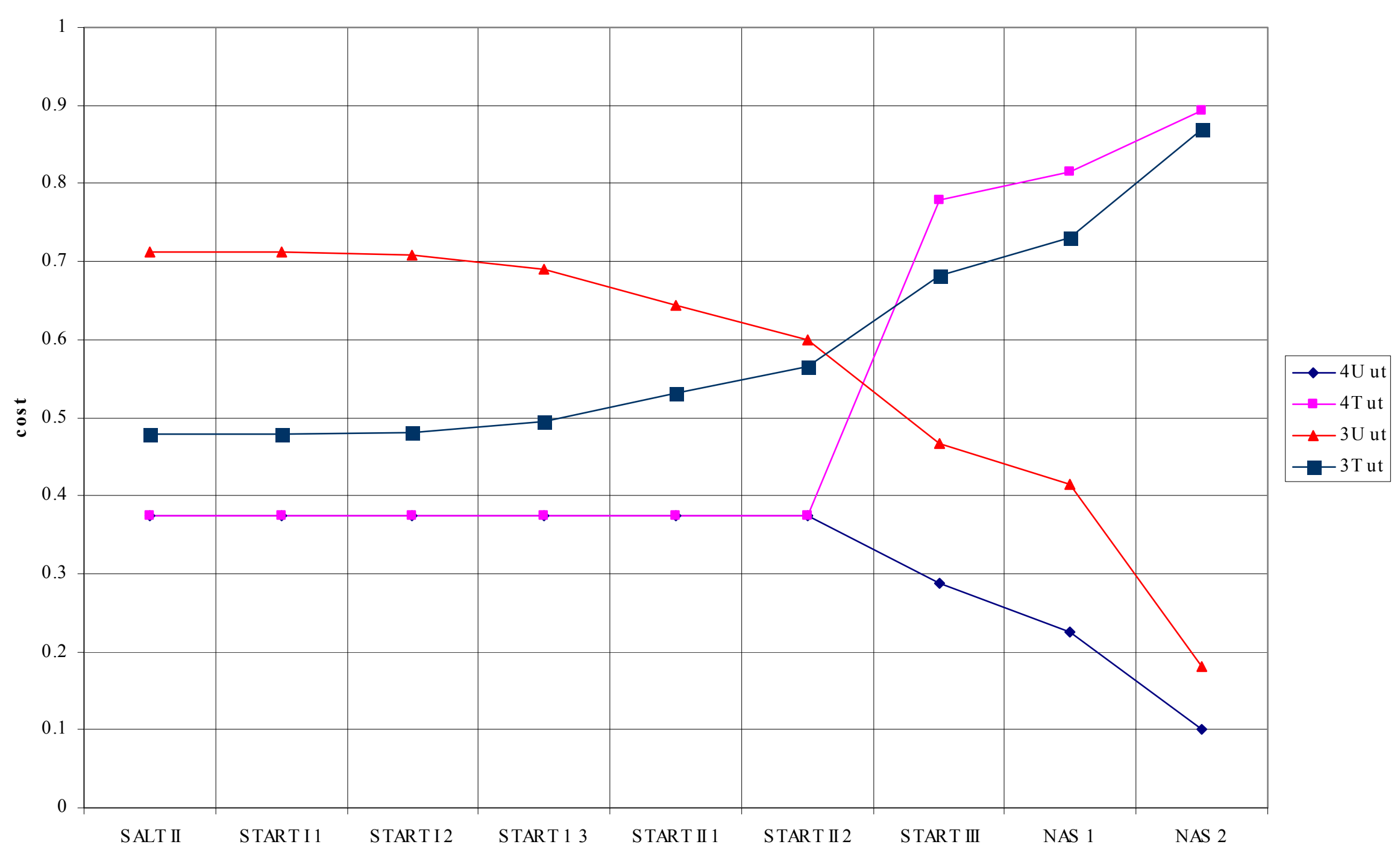


Fig. 17. Cost of node 7 forconflict between sides $U \& P$ and sides $U \& T$

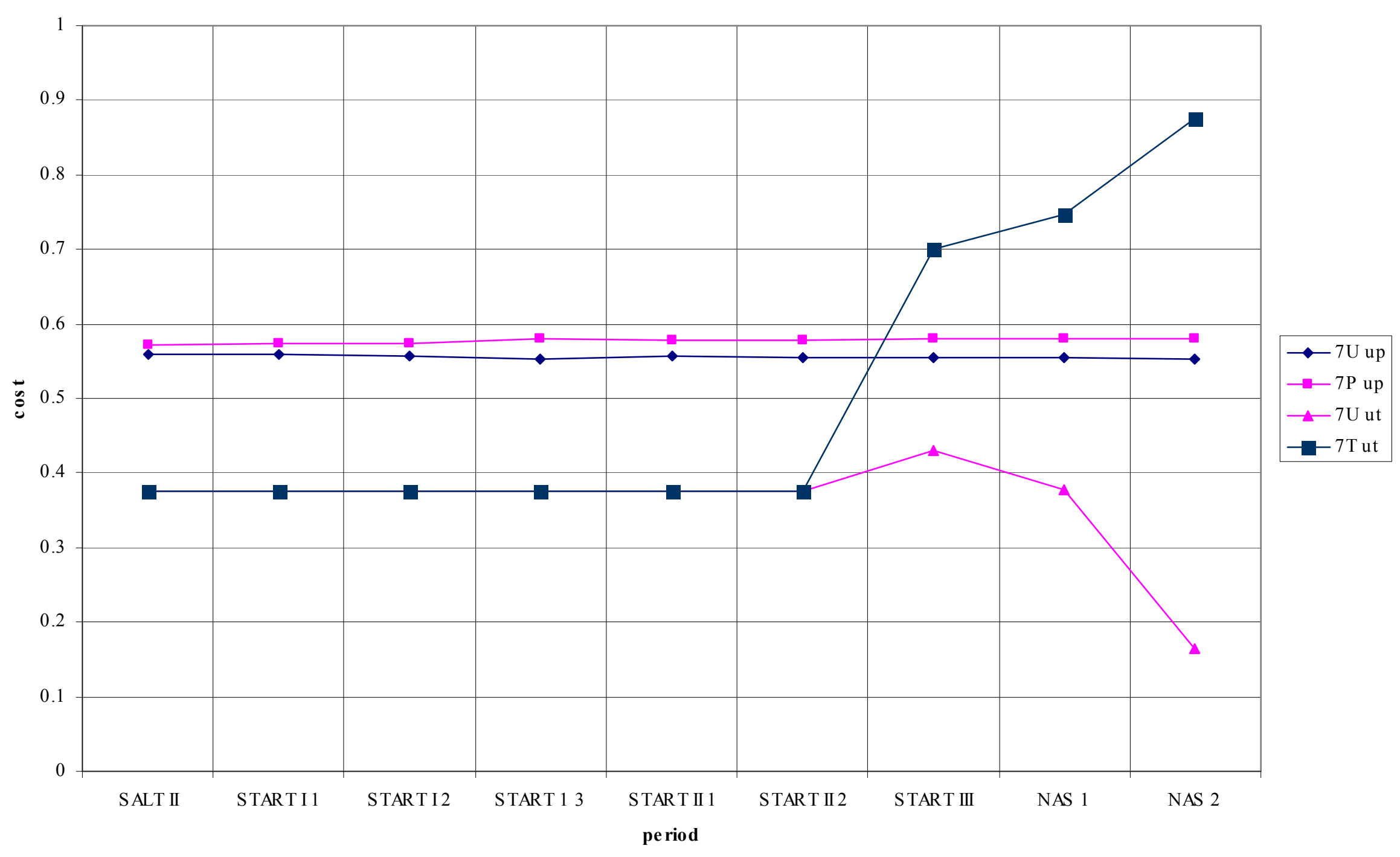


node 7 decis ion costs

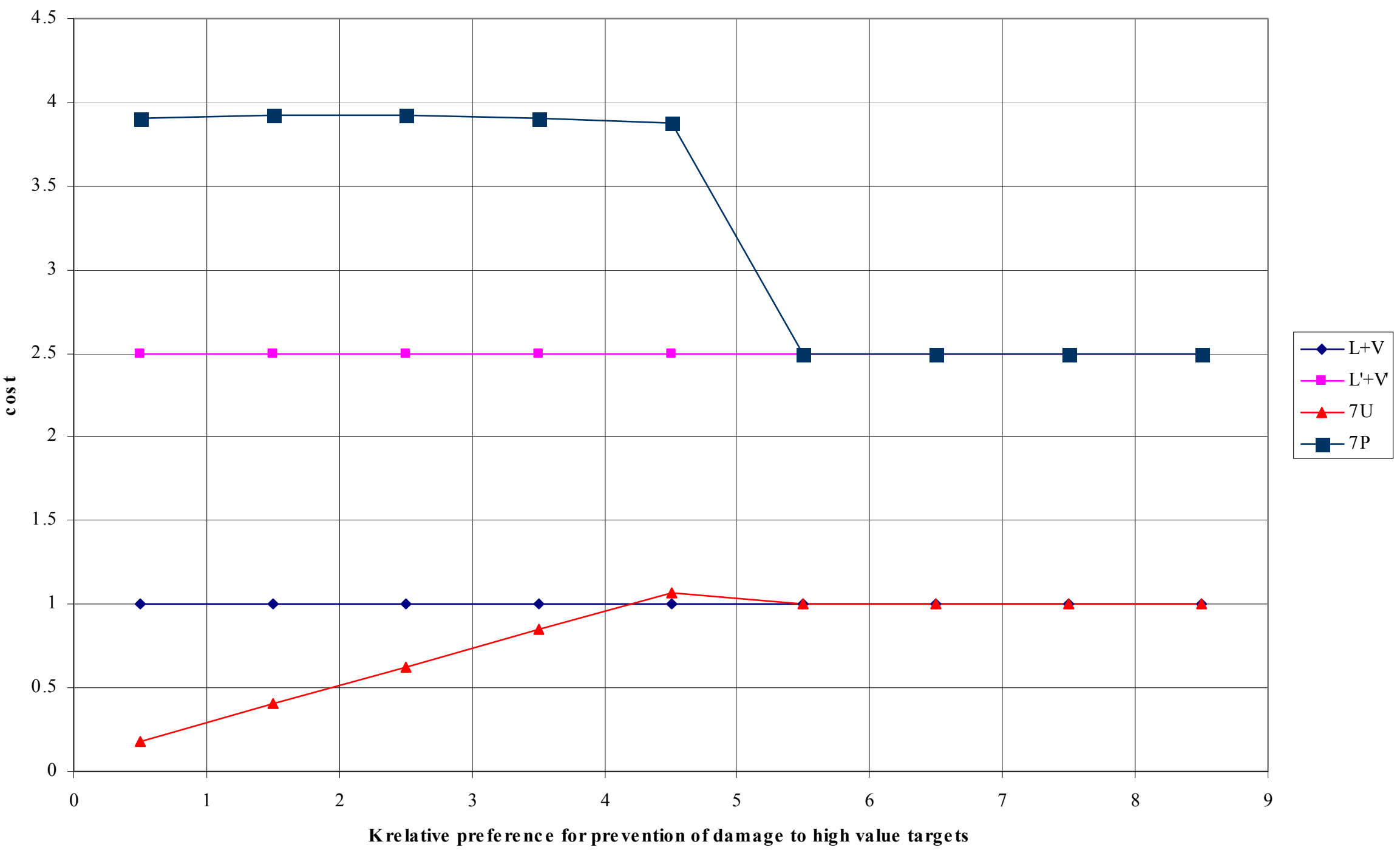




\section{Trilateral Offensive Observations}

- Interaction between $\mathrm{U} \& \mathrm{P} \approx$ bilateral

- Military targets only

- U incentive to destroy small $\mathrm{T}$ forces

- produces incentive for $\mathrm{T}$ to preempt

- stability determined by least stable dyad

- Including high value targets

- U preference for survival of its high value targets

- Reduces its strike incentive

- Eliminates T's incentive to preempt, producing inaction 


\section{Trilateral Engagements w/Defenses}

- U \& P at current levels

- P at current \& larger

- U.S. adds boost or midcourse interceptors

- Optimize U-P \& U-T interactions simultaneously 
Firs $t$ s trike cos ts C1

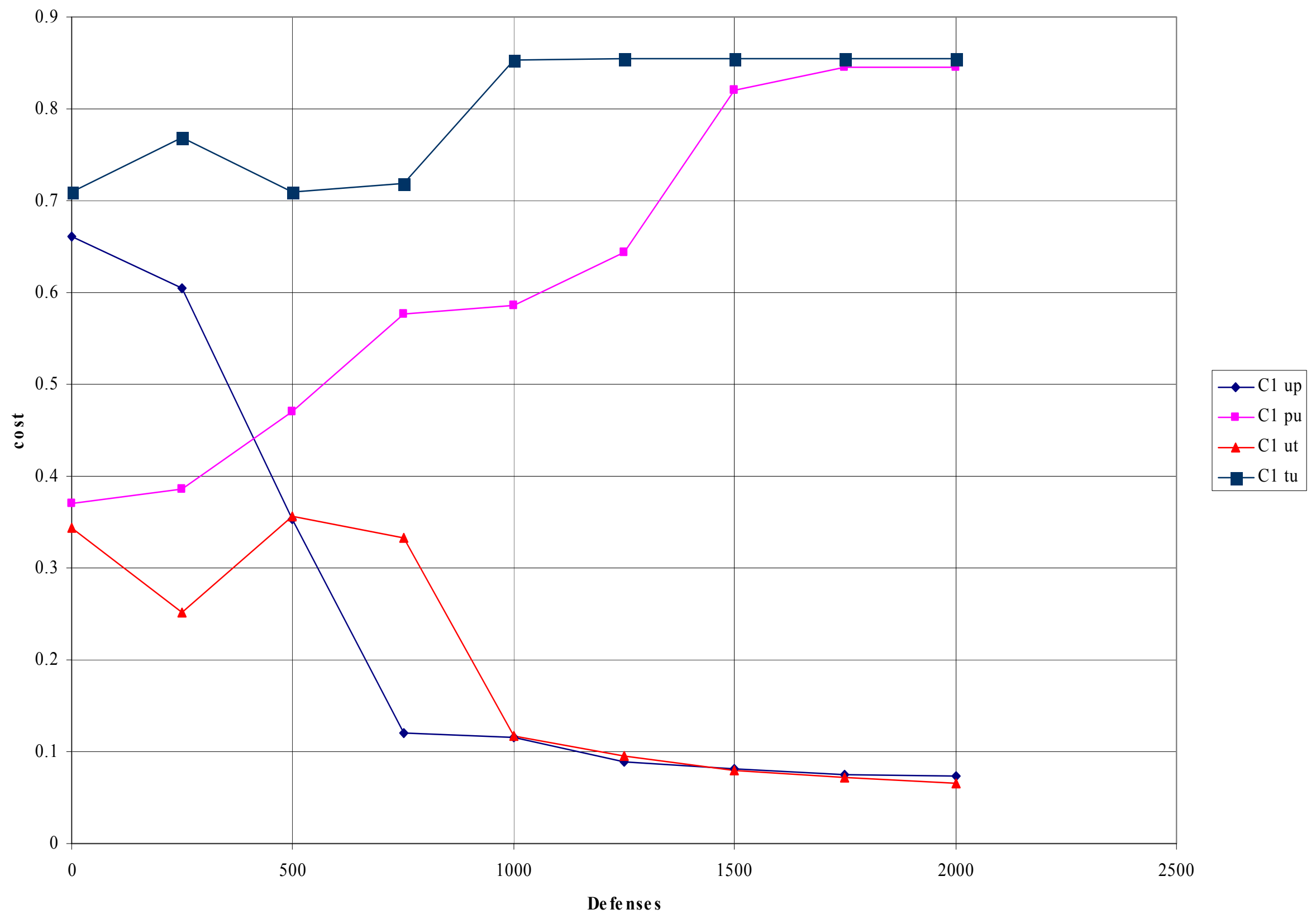


Fig. 21. Cost of node 7 for both $U \& P$ and $U \& T$

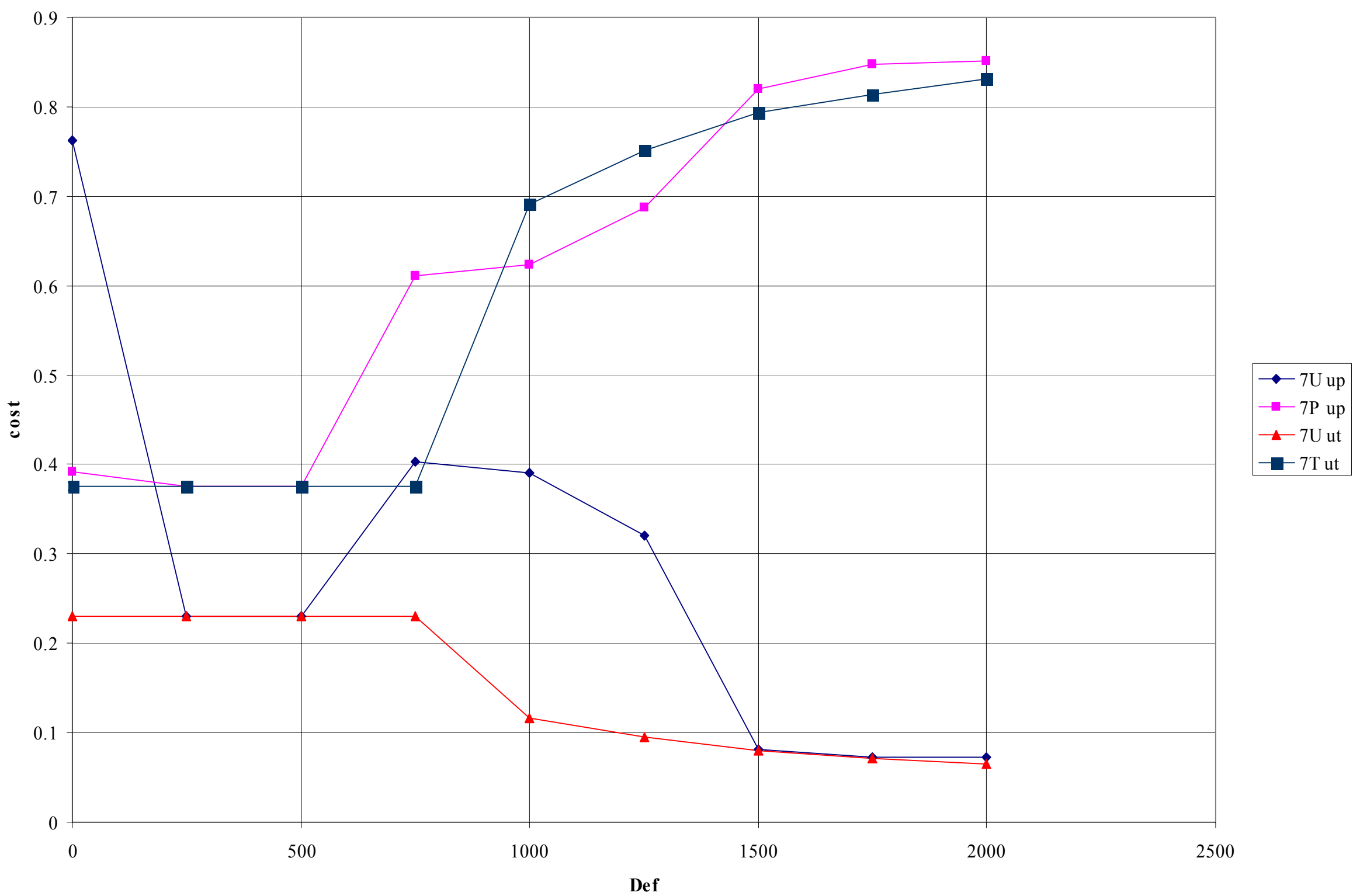


Fig. 10. Cost of node 7

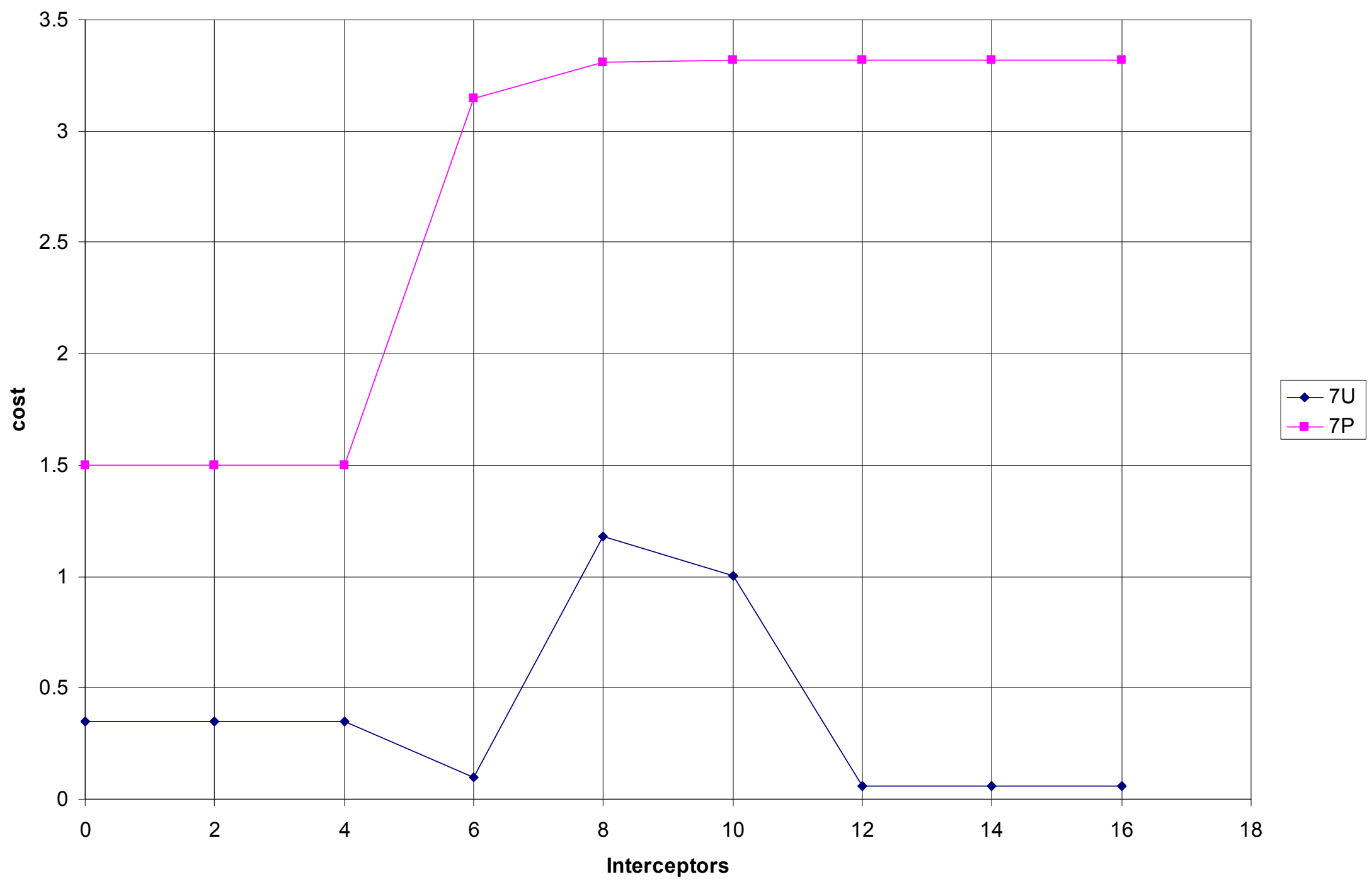




\section{Trilateral w/ Defense Observations}

- U-P interaction $\approx$ bilateral

- Barrier to large defenses

- Removal of U-P barrier by freedom to mix

- Permits U defenses against $T$

- Military targets only

- Produce U strike incentives on T

- No recourse by $\mathrm{T}$

- Stability set by least stable dyad

- High value targets make small U defenses stable 


\section{Summary \& Conclusions Bilateral Interactions}

- Current offenses do not produce strike incentives

- Though large, asymmetrical reductions could

- Stable for large reductions in forces, deterrence

- High value targets alter incentives

- Preference to attack high value increase

- Preference for defense of high value decrease

- Modest defenses do not impact stability

- Large, unilateral defenses could

- Can trade offenses for large defensees stably 


\section{Summary \& Conclusions Trilateral Interactions}

- Offensive interactions

- Military targets: large force has incentive to destroy small \& weak has incentive to preempt

- High value targets: preference for survival reduces strike \& preemption incentives

- Defensive interactions

- Military targets: barrier to large defenses

- Removed by freedom to mix

- High value targets make modest defenses stable 


\section{Summary \& Conclusions Game Theoretic Issues}

- Game theory adequate for bi \& trilateral interactions with and without defenses

- Rational acts minimize cost, produce Nash equilibria

- Uncoordinated attempts to avoid being struck produce strikes and preemption

- Uncertainty plays a critical role

- Decisions based on other's cost \& objective

- Neither known with precision 


\section{Summary \& Conclusions Academic Analyses}

- "Game completely stable, tho advantage to striking $1 \mathrm{st}$ "

- academics assume $\mathrm{C}_{1}>\mathrm{L}$

- "General nuclear war so horrible states would avoid"

- military strikes on military targets--not just general war

- "Game can be made to conform to the classical logic of war by assuming payoff to a successful first strike is greater than the payoff to submitting"

- Agreed: extension to $\mathrm{C}_{1}<\mathrm{L}$ performed above

- "Historical cases could be used to evaluate models"

- increase confidence in ability to explain nuclear crises 